\title{
Targeting ONOO-/HMGB1/MMP-9 Signaling Cascades: Potential for Drug Development from Chinese Medicine to Attenuate Ischemic Brain Injury and Hemorrhagic Transformation Induced by Thrombolytic Treatment
}

\author{
Hansen Chen Binghe Guan Jiangang Shen \\ School of Chinese Medicine, The University of Hong Kong, and The University of Hong \\ Kong-Shenzhen Institute of Research and Innovation (HKU-SIRI), Hong Kong, SAR, China
}

\section{Key Words}

Chinese medicine $\cdot$ Hemorrhagic transformation - Ischemic stroke · Tissue plasminogen activator · Natural compounds · Peroxynitrite $\cdot$ High-mobility group box 1 protein $\cdot$ Matrix metalloproteinase-9

\section{Abstract}

Stroke is the leading cause of death and disability worldwide, and ischemic stroke accounts for more than $85 \%$ of the stroke incidence. Tissue plasminogen activator (t-PA) is the only FDA-approved drug for ischemic stroke treatment with a narrow treatment time window of $4.5 \mathrm{~h}$. Hemorrhagic transformation (HT) is a severe complication of delayed t-PA treatment in ischemic stroke. Thus, it is critically important to develop combination therapies to reduce HT and extend the therapeutic time window of t-PA. Current progress suggests that peroxynitrite $\left(\mathrm{ONOO}^{-}\right)$/high-mobility group box 1 protein (HMGB1)/matrix metalloproteinase-9 (MMP-9) signaling cascades could be important for attenuating HT during thrombolytic treatment for acute ischemic stroke. Recently, important progress has been made in seeking for natural compounds from Chinese medicine for reducing ischemic stroke injury, with some of them targeting $\mathrm{ONOO}^{-} / \mathrm{HMGB} 1 / \mathrm{MMP}-9$ signaling cascades. Herein, we analyze the roles and interactions of these three targets in mediating $\mathrm{HT}$; subsequently, we summarize the potential compounds from Chinese herbal medicine for attenuating HT and analyze the related targets. Finally, we raise the potential issues to be addressed in further development of these compounds as combination therapy. 
Chen et al.: Targeting ONOO-/HMGB1/MMP-9 Signaling Cascades

\section{Introduction}

Stroke is the second leading cause of death, and ischemic stroke accounts for about $85 \%$ of stroke cases [1]. Tissue plasminogen activator (t-PA) remains the only FDA-approved therapy for acute ischemic stroke [2]. Early recanalization with t-PA infusion indeed improves the outcome of ischemic stroke, as suggested by observational studies [3], placebo-controlled trials $[4,5]$ and meta-analyses [6, 7]. However, t-PA has a restrictive time window of $4.5 \mathrm{~h}[8]$. Beyond this, t-PA treatment increases 10 -fold the risk of hemorrhagic transformation (HT), a bleeding into the ischemic brain, which accounts for $10-40 \%$ of ischemic stroke cases with increased morbidity and mortality [9]. Therefore, developing methods to reduce HT is critically important to extend t-PA's therapeutic window and increase its eligibility for ischemic stroke.

Recent studies propose potential solutions by using combination therapies with t-PA to reduce $\mathrm{HT}$ and improve therapeutic outcomes $[10,11]$. Those therapies mainly target matrix metalloproteinase-9 (MMP-9), which is an important target mediating HT [11]. In our previous study, we have reported that reactive nitrogen species (RNS), especially peroxynitrite $\left(\mathrm{ONOO}^{-}\right)$, play an important role in mediating MMP-9 activation and HT in a rat middle cerebral artery occlusion (MCAO) model [12]. In the process, high-mobility group box 1 protein (HMGB1) appears to be a critical signaling molecule to interact with $\mathrm{ONOO}^{-}$and MMP-9 $[13,14]$. The interaction of HMGB1, $\mathrm{ONOO}^{-}$and MMP-9 participates in the pathological process in cerebral ischemia injury. Hence, strategies targeting this signaling cascade could be promising for reducing t-PA-induced HT in ischemic stroke.

Research on adjunct therapy has not been translated into clinical practice yet. Choosing low-toxicity agents is important for the development of adjunct therapy and its further translation into clinical practice. Chinese medicine has been used for treatment of ischemic stroke for thousands of years. Interestingly, many active compounds from Chinese medicine have been demonstrated with good safety profiles, some of which are FDA approved, such as baicalin and catechin [15]. More importantly, studies on herbal compounds revealed their strong protective effects by reducing cerebral ischemia-reperfusion injury, including decreasing infarct volume, brain edema and blood-brain barrier (BBB) damage, suppressing brain inflammation, and improving the neurological outcomes [16, 17]. Some of the compounds, such as baicalin, tanshinone IIA and resveratrol, could inhibit ONOO- $^{-}$MMP-9/ HMGB1 signaling cascades in ischemic stroke models, which indicates their potential for reducing HT.

Herein, we first summarize the roles of $\mathrm{ONOO}^{-}, \mathrm{HMGB} 1$ and MMP-9 in mediating HT with delayed t-PA treatment in ischemic stroke. Based on these targets, we discuss the potential of representative single compounds from Chinese medicine as combined therapy with t-PA to reduce $\mathrm{HT}$, with a focus on the modulating effects of those compounds on $\mathrm{ONOO}^{-}, \mathrm{HMGB} 1$ and MMP-9. Finally, we discuss the important issues that need to be addressed in future development of those compounds as adjunct therapies.

\section{Mechanisms of t-PA-Induced HT}

Multiple mechanisms have been identified which mediate HT after delayed t-PA treatment in ischemic stroke, as addressed by several review articles [10, 18-21]. Among various targets, MMP-9 is a well-studied and established factor contributing to HT in both human and animal studies [22-24]. Recently, we found that $\mathrm{ONOO}^{-}$also significantly participated in mediating HT, possibly via regulating MMP-9 activation in an ischemic stroke model with t-PA treatment [12]. In addition, HMGB1, which is an important molecule in mediating brain inflammation, was also shown to induce MMP-9 production and BBB damage [13]. ONOO-, 
HMGB1 and MMP-9 may synergistically contribute to HT during ischemic stroke with t-PA treatment. In the following section, we focus on these three targets and discuss their potential interaction as a pathway in inducing HT.

\section{Role of $\mathrm{ONOO}^{-}$in $\mathrm{HT}$}

Recanalization after t-PA infusion causes cerebral ischemia-reperfusion injury. Ischemic brains produce a large amount of reactive oxygen species (ROS) and reactive nitrogen species (RNS) [25]. Superoxide $\left(\mathrm{O}_{2}{ }^{-}\right)$and nitric oxide (NO) are representative free radicals in cerebral ischemia-reperfusion injury. They can react with each other extremely rapidly to form $\mathrm{ONOO}^{-}$ with a diffusion limit $\left(\mathrm{k}_{2}=4.7 \times 10^{9} \mathrm{~m}^{-1} \mathrm{~s}^{-1}\right)$. $\mathrm{ONOO}^{-}$was increased at about $4 \mathrm{~h}$ and peaked at around $48 \mathrm{~h}$ after reperfusion [26]. $\mathrm{ONOO}^{-}$induces tyrosine nitration of proteins through adding the nitro group to the hydroxyl group of tyrosine residues [27]. The nitrotyrosine level in the peri-infarct area was about two times higher than that in the core area at $1 \mathrm{~h}$ of reperfusion after ischemia, and persisted until $48 \mathrm{~h}$ after reperfusion [28]. Consistently, 3-nitrotyrosine was also increased in the plasma of stroke patients [29]. ONOO- has far more activity than its precursors [30,31]. For example, $\mathrm{ONOO}^{-}$easily penetrates the lipid layers of the cell membrane, inhibits mitochondrial respiration [32, 33], induces protein nitration [34, 35], lipid peroxidation [36], causes DNA damage [37] and inactivates multiple ion channels and enzymes $[38,39]$. Peroxynitrite decomposition catalysts (PDCs) can neutralize $\mathrm{ONOO}^{-}$to form nontoxic nitrates. FeTMPyP, a representative PDC, significantly prevented neuronal apoptosis and death, reduced the cerebral infarct size and improved functional outcomes in rodent transient ischemic stroke models, with a therapeutic time window up to $6 \mathrm{~h}[40,41]$. Recently, we found that FeTMPyP co-treatment with t-PA significantly reduced HT induced by delayed t-PA treatment in a rat MCAO model [12]. The protective effect of FeTMPyP could be attributed to inhibiting $\mathrm{ONOO}^{-}$-mediated MMP-9 production and activation [12]. Uric acid is an $\mathrm{ONOO}^{-}$scavenger, considered as a potential neuroprotective agent for ischemic stroke treatment [42]. Uric acid treatment significantly reduced the infarct size by $>70 \%$ in a rat MCAO model [43]. A combination of uric acid with t-PA synergistically reduced the cerebral infarct volume and attenuated neurological deficits in a rat thromboembolic model [44]. Moreover, a recent meta-analysis including 10 studies with 8,131 ischemic stroke patients revealed that high serum uric acid was associated with good neurological outcomes [45]. These works strongly indicate that $\mathrm{ONOO}^{-}$plays an important role in mediating t-PA-associated HT and neurological deficit.

\section{Role of MMP-9 in HT}

BBB damage is a critical process of HT, and MMP-9 activation is important for BBB opening [23]. Pro-MMP-9 is a $92-\mathrm{kDa}$ type IV collagenase, and the propeptide domain is removed when pro-MMP-9 is activated [46]. Active MMP-9 is capable of degrading the neurovascular matrix, including collagen, fibronectin and laminin, and disrupting tight junctions [47-50]. MMP activation and BBB opening simultaneously occur in ischemic brains. After stroke, plasma MMP-9/-2 activities were increased within 3-8 h, and early BBB opening occurred within 3-6 h, following early HT at 18-24 h [51, 52]. Neutrophils are a critical source of MMPs in BBB disruption in ischemic brain injury [51]. Within 30 min of cerebral ischemia, circulating leukocytes adhere to vascular endothelial cells; by $6 \mathrm{~h}$, neutrophils have entered ischemic brains [23]. Increased MMP-9 mRNA was found in human peripheral leukocytes at 3-5 $\mathrm{h}$ after stroke, and the peak of MMP-9 activity was at 6-8 $\mathrm{h}$ and returned to baseline by $24 \mathrm{~h}$ [23]. MMP-9 activity was also significantly enhanced in human ischemic brains [53, 54]. Moreover, MMP-9 in the ischemic core was found to be mostly localized to the blood vessels, infiltrated neutrophils and microglials, while MMP-9 in the peri-infarct area was greatly localized to microglial cells [54]. 
MMP-9 plays an important role in cerebral ischemia injury. Broad-spectrum or specific MMP-9 inhibitors significantly reduced neuronal damage in cerebral ischemia models [55, 56]. MMP-9-neutralizing antibody also significantly reduced the brain infarct volume after cerebral ischemia [57]. Consistently, MMP-9 knockout mice showed attenuated brain infarct after cerebral ischemia [58]. More importantly, MMP-9 greatly contributes to BBB damage during cerebral ischemia [24, 59]. MMP-9 knockout in mice protected from BBB disruption in a cerebral ischemia model [58]. MMP-9 siRNA or shRNA treatment reduced Evans blue and IgG extravasation at $24 \mathrm{~h}$ of reperfusion in rodent ischemic stroke models [60, 61]. In addition, broad-spectrum or specific MMP-9 inhibitors also reduced BBB damage in cerebral ischemia models $[49,56,62]$. Those lines of evidence indicate that MMP-9 plays an important role in mediating BBB damage during ischemic stroke.

It has been reported that treatment with $\mathrm{t}-\mathrm{PA}$ promoted neutrophil degranulation and MMP-9 release [63], and significantly upregulated MMP-9 levels in ischemic brains [64]. t-PA knockout mice showed lower MMP-9 levels in ischemic brains than wild-type mice [65]. MMPs are responsible for degradation of the extracellular matrix around cerebral blood vessels and neurons, leading to BBB opening and hemorrhage [52]. Inhibition of MMPs with broad-spectrum inhibitors significantly decreased the incidence of delayed t-PA treatmentinduced HT and mortality in rodent ischemic stroke models [64, 66-69]. Those preclinical studies suggest that MMP-9 mediates delayed t-PA-induced HT in ischemic stroke. Clinical trials indicate that early plasma MMP-9 level is correlated with infarct severity and BBB damage in stroke patients, and the MMP-9 level at $3 \mathrm{~h}$ could predict hemorrhagic complications [70, 71]. Therefore, MMP-9 is an important molecular target in mediating HT in ischemic brains with delayed t-PA treatment.

\section{Role of HMGB1 in HT}

Recent progress draws attention to the roles of HMGB1 in leukocyte adhesion, MMP activation and BBB disruption in ischemic stroke [23]. HMGB1 is a single-polypeptide chain with 215 amino acids containing two positively charged DNA binding motifs, HMG-box A (residues 1-79) and B (residues 89-163), and an acidic C terminus (residues 186-215) with aspartic or glutamic acid residues [72, 73]. HMGB1 serves not only as an architectural transcription factor in the nucleus but also as extracellular signaling after release [74, 75]. HMGB1 can either be secreted from activated macrophages, dendritic cells and natural killer cells or passively leaked from necrotic or injured cells [76, 77]. Active release of HMGB1 involves posttranslational modification of HMGB1, including hyperacetylation of lysine residues [77, 78], phosphorylation of serine residues [79] and oxidation of cysteine residues [80]. After release, HMGB1 can bind with RAGE and Toll-like receptors (TLR2, TLR4) and trigger inflammation by inducing cytokines [81]. Elevated HMGB1 was found early at 2-4 h in ischemiareperfused brains $[75,82]$. HMGB1 promoted neuroinflammation in rats with intracerebral hemorrhage (ICH) [83]. Antibody against HMGB1 reduced BBB permeability and infarct volume in rodent cerebral ischemic models [82]. As an HMGB1 inhibitor, glycyrrhizin binds to HMGB1 and inhibits its cytokine-promoting activities. Glycyrrhizin attenuated oxidative stress-mediated MMP activity, inhibited inflammation and apoptosis in ischemic brains [84], and reduced ICH-induced cellular injury [85]. However, a recent study reported that HMGB1 promoted fibrinolysis and reduced t-PA-mediated neurotoxicity [86]. The controversial effects of HMGB1 might be related to the amount of HMGB1 release from cells and its microenvironment.

Relationship among $\mathrm{ONOO}^{-}, \mathrm{HMGB1}$ and MMP-9

As mentioned, $\mathrm{ONOO}^{-}$, MMP-9 and HMGB1 are important mediators of cerebral ischemia injury and BBB disruption. They intimately interact with each other, which may work together 
as a pathway in mediating HT induced by delayed t-PA treatment in ischemic stroke. In the following section, we will discuss the interaction between these three factors.

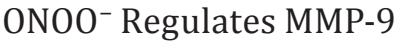

There is an intrinsic relationship between $\mathrm{ONOO}^{-}$and $\mathrm{MMP}-9 . \mathrm{ONOO}^{-}$-activated MMPs lead to tight junction disruption and neurovascular unit damage during ischemic stroke [8789]. $\mathrm{ONOO}^{-}$may induce MMP-9 expression by activating $\mathrm{NF}-\kappa \mathrm{B}$ [90]. $\mathrm{ONOO}^{-}$induced proMMP-9 activation in the presence of glutathione via S-glutathionylation [91]. FeTMPyP, a representative PDC, decreased MMP-9 activity and protected from neurovascular injury in ischemic stroke [92]. Consistently, FeTPPS, another PDC, suppressed MMP-9 activation and improved the neurological outcome in hemoglobin-induced hemorrhagic stroke models [93, 94]. In addition, uric acid reduced the serum active MMP-9 level of ischemic stroke patients, indicating that $\mathrm{ONOO}^{-}$could be associated with MMP-9 in human ischemic stroke [95]. These works suggest that $\mathrm{ONOO}^{-}$activates MMP-9 in ischemic stroke, contributing to neurovascular unit damage and HT.

\section{ONOO- $^{-}$Regulates HMGB1}

HGMB1 activation highly depends on its redox state [96]. The NADPH oxidase-mediated HMGB1 signaling pathway contributes to cerebral ischemia-reperfusion injury. Edaravone, an antioxidant, exerted neuroprotective effects through inhibiting HMGB1 signaling [97]. Baicalin, a flavonoid isolated from the medicinal plant Scutellaria baicalensis Georgi, was reported to inhibit HMGB1 release and improve survival in experimental sepsis [98]. In infarct myocardium, PDCs suppressed HMGB1 and decreased infarct size, suggesting that $\mathrm{ONOO}^{-}$could induce HMGB1 release from cardiac cells [99]. As an $\mathrm{ONOO}^{-}$scavenger, uric acid prevented translocation of HMGB1 release from endothelial cells [100]. However, the relationship between $\mathrm{ONOO}^{-}$and $\mathrm{HMGB} 1$ release in ischemic brains is still unclear, and the impact of HMGB1 release on BBB disruption and HT in delayed t-PA treatment remains unknown and needs further investigation.

HMGB1 Regulates MMP-9

It is reported that HMGB1 could promote MMP-9 expression from astrocytes and neurons in ischemic brains, predominantly via TLR4 [13]. HMGB1 is closely related to oxidative stress, MMP activation and BBB disruption [13, 83, 84, 96]. In ischemic stroke patients, an increased plasma HMGB1 level was correlated with MMP-9 level and poor clinical outcome [101].

According to those studies, $\mathrm{ONOO}^{-}$may induce HMGB1 activation, subsequently mediating MMP-9 activity and expression and inducing BBB damage and HT. Though the interaction of those three factors needs further study, it is clear that they all significantly contribute to cerebral ischemia injury and BBB disruption, eventually leading to HT. Thus, therapies acting on those targets are promising in reducing HT and extending the therapeutic time window of t-PA.

\section{Active Compounds from Chinese Herbal Medicine for Targeting ONOO-/HMGB1/} MMP-9 Signaling Cascades and Potential for Treating Acute Ischemic Stroke

Traditional Chinese medicine (TCM) has been practiced for more than 2,000 years, and more than 100 herbs are used for treating ischemic stroke [102]. A recent summary of systematic review articles suggests that TCM has beneficial effects on stroke though highquality clinical trials are needed [103]. Natural products from Chinese herbal medicine have been considered as important sources of drug discovery [104]. Many natural compounds 
Fig. 1. The structure of baicalin.

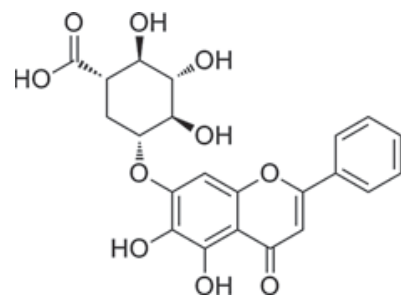

revealed their bioactivities in ameliorating cerebral ischemic injury [105]. Hence, the development of natural compounds from Chinese medicine is a promising direction for protecting ischemic brains. Herein, we present a representative selection of compounds based on the targets discussed, including $\mathrm{ONOO}^{-}$, HMGB1 and MMP-9. Totally, 7 compounds are selected, and their potential for reducing HT, BBB damage and brain injury are discussed in the following section.

\section{Baicalin}

Baicalin is a flavonoid compound isolated from Chinese medicine radix of S. baicalensis Georgi, a commonly used TCM herb for removing interior heat according to TCM theory [106]. S. baicalensis Georgi is usually used for attenuating various kinds of bleeding due to the accumulation of interior heat in TCM pathology. Baicalin is a flavone, and its chemical structure is shown in figure 1. A recent systemic genome microarray analysis revealed that baicalin treatment regulated multiple pathways in an MCAO model [107]. Our group and others showed that baicalin treatment decreased the cerebral infarct volume, attenuated neurotoxicity and suppressed neuroinflammation both in transient and permanent rodent cerebral ischemia models [108-110]. Baicalin exerts anti-inflammatory effects via modulating the TLR4/NF- $\kappa B$ pathway and downregulating its downstream factors, including inducible nitric oxide synthase (iNOS), cyclooxygenase-2, IL-1 $\beta$ and TNF- $\alpha$ in permanent and transient cerebral ischemia models [110-112]. Antiapoptotic effects of baicalin were also observed in a focal cerebral ischemia injury model, possibly via downregulating protease-activated receptor-1 [113]. In addition to ischemic stroke models, baicalin also exerted protective effects on hemorrhagic stroke models and reduced brain edema and apoptosis in a time- and dose-dependent manner [114].

Previously, we found that baicalin could directly scavenge $\mathrm{ONOO}^{-}$, as evident by mass spectrometry analysis. Moreover, baicalin reduced $\mathrm{ONOO}^{-}$in human neuroblastoma SH-SY5Y cells and rat ischemic brains, subsequently attenuated neurotoxicity and reduced the brain infarct volume [108]. In addition, baicalin also reduced $\mathrm{NO}$ and $\mathrm{O}_{2}^{-}$in tert-butyl hydroperoxide-treated endothelial cells, and hence prevented the formation of $\mathrm{ONOO}^{-}$[115]. Baicalin could inhibit iNOS and cyclooxygenase-2, which may account for reduced $\mathrm{NO}$ and $\mathrm{O}_{2}^{-}$[115]. In addition to scavenging ROS and RNS, baicalin treatment at 2 and $12 \mathrm{~h}$ after MCAO onset reduced MMP-9 expression, protected tight junction proteins, attenuated BBB damage and decreased brain edema in a rat MCAO model [116]. Consistently, baicalin also inhibited MMP-9 expression in rat ICH brains, reducing BBB damage and brain edema [117]. The exact mechanisms of how baicalin inhibits MMP-9 expression are still not clear, and several putative targets may be involved. Inhibition of NF- $\kappa \mathrm{B}$ may reduce the transcription of MMP-9 gene in stroke models, eventually reducing MMP-9 expression [117]. Inhibition of the p38 MAPK pathway may also account for the suppression of MMP-9 expression [118]. Recently, we 
Fig. 2. The structure of resveratrol.

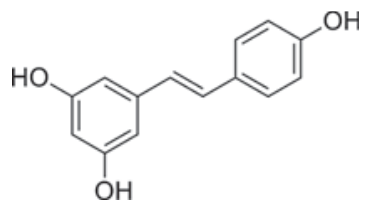

found that inhibiting $\mathrm{ONOO}^{-}$with PDC significantly reduced MMP-9 expression [12]. Therefore, scavenging $\mathrm{ONOO}^{-}$and suppressing MMP-9 could be the critical molecular mechanisms contributing to the neuroprotective effects of baicalin in cerebral ischemia reperfusion injury.

Recent studies indicate that baicalin could inhibit HMGB1 release in sepsis and vascular disease models $[98,119]$. Baicalin also inhibited the release of HMGB1 in lipopolysaccharide (LPS)-challenged human endothelial cells, subsequently reducing the production of the proinflammatory cytokines TNF- $\alpha$ and IL-6, and inhibiting vascular hyperpermeability and leukocyte migration [119]. Similarly, baicalin inhibited HMGB1 release in LPS-treated macrophages [98]. Baicalin did not affect the transcription or translation of HMGB1; rather, it inhibited the cytoplasmic translocation of HMGB1 in macrophages [98]. It seems that several mechanisms may be involved in inhibiting HMGB1 translocation. Baicalin was shown to enhance histone deacetylase (HDAC) expression and activity in chronic obstructive pulmonary disease [120]. HDACs are important molecules for suppressing HMGB1 release [121, 122]. Hence, increasing HDACs may be one of the possible mechanisms of baicalin in inhibiting HGMB1 translocation. Protein kinase C (PKC) activation could lead to phosphorylation of HMGB1 and subsequent translocation [79]. Baicalin inhibited PKC in brain microvascular endothelial cells and hippocampal slices in vitro under oxygen glucose deprivation condition or with NMDA treatment $[123,124]$. Suppression of free radical-mediated oxidative stress could also inhibit HMGB1 release as suggested by previous research [97]. However, whether baicalin can inhibit HMGB1 release in a stroke model needs further investigation.

As baicalin reveals pleiotropic effects by attenuating cerebral ischemic injury and has the capacity to target $\mathrm{ONOO}^{-} / \mathrm{HMGB} 1 / \mathrm{MMP}-9$ signaling cascades, we propose that this compound is a promising candidate for combination therapy with t-PA in treating acute ischemic stroke.

\section{Resveratrol}

Resveratrol is a natural phenol found in the Chinese herb Polygonum cuspidatum and other sources such as grapes and eucalyptus [125]. The structure of resveratrol is shown in figure 2. Resveratrol is a potential drug candidate for treatment of ischemic stroke, as summarized in a recent review article [126]. Resveratrol exhibited multiprotective effects, such as antiapoptotic [127, 128], antioxidative [129], anti-inflammatory [130] and antiexcitotoxic effects $[131,132]$. Resveratrol has a therapeutic time window up to $6 \mathrm{~h}$ after ischemic onset; it reduced infarct volume, attenuated microglial activation and suppressed cytokine production and free radical generation [130]. Proteomic analysis revealed that resveratrol treatment in a rat MCAO model regulated various proteins related to oxidative stress and energy metabolism [133]. Pretreatment with resveratrol even 14 days before MCAO reduced the brain infarct volume by $33 \%$ in rats, which was mediated by silent mating type information regulation 2 homolog 1 (SIRT1) [134]. Nrf2 activation is another mechanism of resveratrol which mediates preconditioning protective effects in a rodent stroke model, possibly through upregulating antioxidant protein expression and maintaining mitochondrial coupling $[135,136]$. Interestingly, resveratrol also provided a protective effect in an experimental 


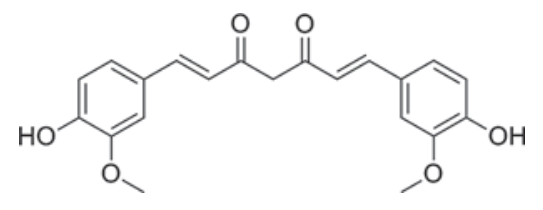

recurrent stroke model through regulating AMP-activated protein kinase (AMPK) and SIRT1 signaling $[137,138]$.

Though not yet confirmed in a stroke model, resveratrol scavenges $\mathrm{ONOO}^{-}$and inhibits protein nitration in several other models [139-141]. Moreover, liquid chromatography with tandem electrospray mass spectrometry showed that resveratrol is a substrate of $\mathrm{ONOO}^{-}$. It could directly scavenge $\mathrm{ONOO}^{-}$and reduce the authentic $\mathrm{ONOO}^{-}$-mediated bovine serum albumin nitrotyrosine, with an $\mathrm{EC}_{50}$ value of $22.7 \mathrm{~mm}$ [142]. In a rat MCAO model, resveratrol treatment at reperfusion increased eNOS expression while decreasing detrimental iNOS expression in ischemic brains [143]. In vitro, resveratrol inhibited iNOS expression in LPStreated mouse glial cells, subsequently reducing NO production [144]. Consistently, resveratrol inhibited iNOS expression and NO production in cortical neurons under oxygen glucose deprivation condition [127]. Inhibition of iNOS could reduce the overproduction of NO, which may eventually contribute to a reduction of $\mathrm{ONOO}^{-}$.

Resveratrol inhibited MMP-9 expression and activity in rodent ischemic brains within $24 \mathrm{~h}$ after MCAO, subsequently reducing BBB damage and brain edema [145, 146]. A recent study adopting a molecular docking strategy showed that resveratrol directly occupied the active site of MMP-9 through interacting with the Glu 402, Ala 417 and Arg 424 residues of MMP-9 [147]. This result explains how resveratrol directly inhibits MMP-9 activity in a stroke model. In addition, in vitro studies showed that inhibition of MMP-9 expression by resveratrol was possibly due to activation of peroxisome proliferator-activated receptor- $\alpha$ and inhibition of extracellular signal-regulated kinases (ERK1/2) [148, 149]. Those lines of evidence suggest that resveratrol is a potent MMP-9 inhibitor for ischemic stroke treatment.

Resveratrol also inhibited HMGB1 release in other systems possibly via suppressing the JAK/STAT1 signaling pathway $[150,151]$, which is important in mediating HMGB1 hyperacetylation and translocation [152]. Sirtuin-1 was recently identified as a novel mediator of deacetylation of HMGB1 [153]. Resveratrol could upregulate sirtuin-1, which may also contribute to inhibiting translocation of HMGB1 [154]. In addition to inhibiting translocation, resveratrol was also shown to decrease HMGB1 expression in an atopic dermatitis mouse model [155]. However, whether resveratrol inhibits HMGB1 in a stroke model is still unknown yet and merits further investigation.

\section{Curcumin}

Curcumin is a polyphenolic compound derived from the Chinese medicine Curcuma longa Linn [156]. The structure of curcumin is shown in figure 3. Notably, curcumin treatment reduced HT of cerebral ischemia in diabetic rats [157]. Curcumin treatment after focal cerebral ischemia significantly and dose-dependently reduced infarct volume, decreased brain edema and BBB damage, improved the neurological outcome and reduced the mortality rate, with a therapeutic time window up to $4 \mathrm{~h}$ [158-160]. Curcumin exhibited antiapoptotic, antioxidative and anti-inflammatory effects in cerebral ischemia, which accounted for attenuated cerebral injury $[160,161]$. It was shown that the antioxidative effect of curcumin was 
Fig. 4. The structure of apocynin.

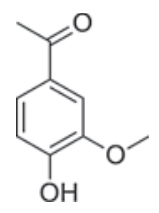

at least partially due to the activation of Nrf2 $[162,163]$. Curcumin also decreased MMP-9 and TNF- $\alpha$ expression in ischemic brains [164]. As a nonspecific NF- $\kappa B$ inhibitor, curcumin seems to inhibit MMP-9 via downregulating NF- $\mathrm{KB}$ activity [165].

Curcumin reduced $\mathrm{ONOO}^{-}$levels and tyrosine nitration in ischemic brains [166]. Curcumin attenuated rat spiral ganglion neuron apoptosis induced by $\mathrm{ONOO}^{-}$and protected from mitochondrial oxidative stress [167]. It also prevented the cerebral vascular endothelial damage induced by the $\mathrm{ONOO}^{-}$donor 3-morpholinosydnonimine (SIN-1) [158]. A direct interaction between curcumin and $\mathrm{ONOO}^{-}$was observed with spectroscopic techniques [168]. Curcumin could also inhibit iNOS and reduce the nitrite/nitrate content in LPS- or TNF- $\alpha$-treated astrocytes in vitro [158]. Consistently, curcumin reduced the nitrite/nitrate level in vivo in a rat thromboembolic model [159].

Curcumin treatment reduced HMGB1 expression in a rat global cerebral ischemia reperfusion model [169]. Similarly, pretreatment with curcumin reduced HMGB1 expression in a cardiac ischemia-reperfusion injury model [170]. Curcumin inhibited HMGB1 release possibly via inhibiting acetylation of lysine residues [171]. Taken together, curcumin may target $\mathrm{ONOO}^{-} / \mathrm{HMGB} 1 / \mathrm{MMP}-9$ signaling cascades and has the potential to ameliorate $\mathrm{HT}$ in ischemic stroke with t-PA treatment.

\section{Apocynin}

Apocynin is derived from the medical plant Picrorhiza kurroa and other sources, and is an NADPH oxidase inhibitor [172]. The structure of apocynin is shown in figure 4. Apocynin treatment reduced the brain infarct size at $24 \mathrm{~h}$ after cerebral ischemia $[173,174]$. Apocynin also attenuated the BBB damage in a hyperglycemic rat MCAO model, possibly through downregulating MMP-9/-2 and protecting tight junction proteins $[175,176]$. More importantly, apocynin attenuated HT, protected BBB integrity and decreased infarct volume in hyperglycemic rats with t-PA treatment [177]. Apocynin inhibited NAPDH oxidase and increased HDACs, and subsequently reduced HMGB1 release and cerebral ischemia damage [178]. Consistently, apocynin also reduced HMGB1 release in ethanol-treated SH-SY5Y cells and primary cortical neurons in vitro [179]. In addition to inhibiting HMGB1, pretreatment with apocynin upregulated bcl-2 expression, but downregulated bax expression, and subsequently inhibited cell apoptosis in a rat MCAO model. Apocynin also reduced proinflammatory cytokine IL-1 $\beta$ in the same model [180]. Apocynin decreased the nitrotyrosine level in ischemic brains [180] as well as other experimental systems [181-186]. The effects of apocynin on scavenging $\mathrm{O}_{2}^{-}$in ischemic brain tissues were also observed in a rat transient focal cerebral ischemia model, which was related to inhibiting the NADPH oxidase isoform Nox2 $[173,187]$. The inhibition or scavenging effects of apocynin on $\mathrm{O}_{2}{ }^{-}$may account for reduced $\mathrm{ONOO}^{-}$production in ischemic brains. It is worth mentioning that apocynin treatment increased the mortality rate in an aged rat MCAO model and failed to reduce the infarct volume and BBB damage [188]. Moreover, apocynin treatment at high dosage increased HT in a transient MCAO mouse model [189]. These results suggest that the effects of apocynin on 
Fig. 5. The structure of glycyrrhizin.

Chen et al.: Targeting ONOO-/HMGB1/MMP-9 Signaling Cascades

Fig. 6. The structure of caffeic acid.
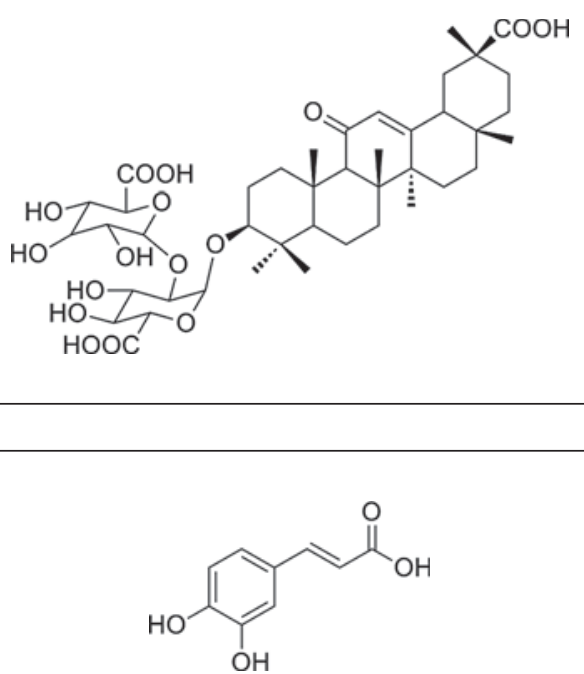

ischemic stroke depend on the age of the subject as well as treatment dosage, and further research should be carefully conducted to address these issues.

\section{Glycyrrhizin}

Glycyrrhizin is a main constituent of herbal medicine Glycyrrhiza glabra, which is used in $60 \%$ of TCM formulas [190]. The structure of glycyrrhizin is shown in figure 5. Glycyrrhizin is a well-known HMGB1 inhibitor. Surface plasmon resonance analysis revealed that glycyrrhizin bound to HMGB1 with a moderate equilibrium dissociation constant value and reduced the interaction of HMGB1 and its receptor RAGE in a traumatic brain injury model [191]. Glycyrrhizin reduced HMGB1 secretion in ischemic brains and downregulated inflammatory factors, including TNF- $\alpha$, iNOS, IL-1 $\beta$ and IL-6 $[84,192]$. An in vitro study showed that glycyrrhizin inhibited the PKC and calcium/calmodulin-dependent protein kinase IV activity in active microglia, subsequently reducing the phosphorylation of HMGB1 and its translocation, resulting in suppression of cytokine expression [192]. Glycyrrhizin also reduced the brain infarct volume and improved neurological outcomes both in a transient ischemic stroke model and an acute hyperglycemia stroke model [84, 192, 193]. Moreover, glycyrrhizin exhibited antiapoptotic effects via inhibiting IL-17A-mediated reduction of bcl-2/bax ratio and cytochrome c release in ischemic brains $[84,194]$. Glycyrrhizin also reduced oxidative stress and NF- $\kappa B$-related brain inflammation in rodent ischemic stroke [195].

Though not yet confirmed in a cerebral ischemia model, glycyrrhizin reduced nitrotyrosine in a gut ischemia-reperfusion model [196], carrageenan-induced lung injury in mice [197] and spinal cord compression injury in mice [198]. The inhibitive effects of glycyrrhizin on MMP-9 were also observed in several studies $[199,200]$. Therefore, glycyrrhizin could be a promising candidate for a combined therapy for reducing HT induced by delayed t-PA treatment, possibly via targeting $\mathrm{ONOO}^{-} / \mathrm{HMGB} / \mathrm{MMP}-9$ signaling cascades.

\section{Caffeic Acid}

Caffeic acid is a phenolic compound found in many medicinal plants [201]. The structure of caffeic acid is shown in figure 6. Caffeic acid treatment significantly and dose-dependently attenuated hippocampal neuron loss and improved the motor function of rats in a global 
Fig. 7. The structure of tanshinone IIA.

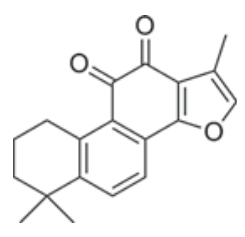

cerebral ischemia model via inhibiting 5-lipoxygenase and NF- $\kappa B$ [202]. Similarly, caffeic acid improved neural viability and synapses, and attenuated memory deficit in a permanent MCAO mouse model [203]. More importantly, caffeic acid treatment for 5 days after ischemia significantly reduced rat brain infarct volume and inhibited astrocyte proliferation at day 14 in a transient MCAO model, indicating the long-term efficacy of caffeic acid [204]. Caffeic acid scavenged $\mathrm{ONOO}^{-}$and reduced $\mathrm{ONOO}^{-}$-mediated tyrosine nitration [205]. In addition, caffeic acid is also an MMP-9 inhibitor with an IC $_{50}$ value of 10-20 nM [206]. Hence, caffeic acid could possibly target $\mathrm{ONOO}^{-} / \mathrm{HMGB} / \mathrm{MMP}-9$ signaling cascades in ischemic stroke to attenuate $\mathrm{HT}$ induced by delayed t-PA treatment.

\section{Tanshinone IIA}

Tanshinone IIA is one of the active ingredients of Salvia miltiorrhiza root. The structure of tanshinone IIA is shown in figure 7. Tanshinone IIA demonstrated an antiapoptotic effect via upregulating blc- 2 expression and downregulating active caspase-3 in the cortex, subsequently reducing neural apoptosis, decreasing the brain infarct volume and attenuating neurological deficit in a rat MCAO model $[207,208]$. In addition, tanshinone IIA scavenged RNS in an ischemic stroke model [209]. Tanshinone also exhibited an anti-inflammatory effect through reducing macrophage migration inhibitory factor and proinflammatory cytokines such as IL- 6 and TNF- $\alpha$ in a rat MCAO model [210]. Tanshinone IIA treatment prevented BBB damage and brain edema via suppressing MMP-9 expression, reducing HMGB1 levels and NF- $\mathrm{\kappa B}$ activation and protecting tight junction proteins in rat transient MCAO models $[211,212]$. Consistently, tanshinone treatment at reperfusion for 15 days inhibited HMGB1 expression and NF- $\mathrm{KB}$ activation, protecting from neuron apoptosis in a rat MCAO model [213]. Inhibition of HMGB1 by tanshinone IIA was also found in a myocardial infarction model, coinciding with attenuated inflammation and oxidative stress [214]. Taken together, tanshinone IIA could protect against ischemia stroke injury and targets HMGB1, MMP-9 and free radicals. Hence, tanshinone IIA is a promising compound for mitigating ischemic stroke injury and attenuating HT induced by t-PA treatment.

\section{Discussion}

In this review article, we have discussed the important roles of $\mathrm{ONOO}^{-} / \mathrm{HMGB}^{-} / \mathrm{MMP}-9$ signaling cascades in mediating neural cell death, infarction enlargement and BBB damage, and their potential roles in mediating HT induced by delayed t-PA treatment. These three factors may work together as a pathway significantly contributing to HT. Thus, targeting $\mathrm{ONOO}^{-} / \mathrm{HMGB} 1 / \mathrm{MMP}-9$ signaling cascades could be an important strategy to reduce HT. Natural compounds from Chinese medicine including baicalin, resveratrol, curcumin, apocynin, glycyrrhizin, caffeic acid and tanshinone IIA have shown the potential to be combined therapies with t-PA and prevent t-PA-mediated HT and ischemic brain injury 
through targeting $\mathrm{ONOO}^{-} / \mathrm{HMGB} 1 / \mathrm{MMP}-9$ signaling cascades. For example, apocynin ameliorated HT in hyperglycemic rats [177]. Similarly, curcumin inhibited HT in a diabetic rat cerebral ischemia model [157]. These studies suggest that apocynin and curcumin have a high potential for further development into adjunct therapies with t-PA. Nevertheless, it has not yet been tested whether most of the other selected compounds could help reduce HT in ischemic stroke with thrombolytic treatment. Although further studies are needed to verify their efficacies in reducing HT, the selected compounds are good candidates for developing adjunct therapies with t-PA, not only because of their efficacies in ameliorating ischemic brain injury and HT but also their good safety profiles. For example, baicalin is an active ingredient in flavocoxid, an FDA-approved medicinal healthy food [15]. Resveratrol is well tolerated by human, as suggested by a recent phase II clinical trial, with the highest dosage of 1,000 $\mathrm{mg}$ twice daily [215]. Similarly, curcumin is also safe for human at a dosage of 1,000 mg daily for 6 weeks [216]. The high tolerance of those compounds in human further makes them potential candidates for translational study.

Nevertheless, the direct effects of those compounds on the 0NOO-/HMGB1/MMP-9 signaling cascades remain to be further addressed. Firstly, whether the selected compounds could target all these three molecules and improve the therapeutic outcome is still unclear. For example, though resveratrol was shown to inhibit HMGB1, studies demonstrating its effects on a stroke model are still lacking. A similar situation applies to other compounds. Secondly, whether the compounds can directly modify the targets needs further investigation. Some studies showed the direct interaction of the compounds with the targets. For example, resveratrol directly binds to the active site of MMP-9, as revealed by a molecular docking study [147], and baicalin directly scavenges $\mathrm{ONOO}^{-}$, as shown by a mass spectrum analysis [108]. However, most of the other studies only observed the phenomenon of the modulatory effects on these targets, and the exact modulatory processes are still unknown. Hence, whether those compounds have the direct effects on the targets or just a consequence of the indirect response to treatments with the compounds remains unclear and merits further investigation.

As for development of those compounds into adjunct therapy, following important issues should be considered. The first issue is the time point for outcome measurement. Most of the preclinical studies only evaluated the HT results within $24 \mathrm{~h}$ after cerebral ischemia [217]. However, HT could occur in both the early and the late phase of cerebral ischemia, even days after stroke [218]. Thus, measuring the HT results at $24 \mathrm{~h}$ is not good enough for thoroughly evaluating the effect of a combination therapy, as prevention of HT at an early stage does not necessarily ensure its protective effects at a late phase. Hence, the observation of HT may be extended to days after ischemia onset. The second issue is the therapy duration. As the measurement time point is extended to days after stroke, whether repeated treatment is more beneficial needs to be addressed further. Repeated treatment may continuously modulate the related targets and enhance the therapeutic effects on HT. On the other hand, treatment in a late phase may cause unfavorable outcomes due to the protective roles of those targets in a late phase of stroke. Evidence has shown that MMP-9 and HMGB1 may be beneficial in a late phase of stroke. In detail, MMP-9 contributes to the remodeling of neuroplasticity [219]. Inhibition of MMP-9 beginning on day 7 after cerebral ischemia increased brain injury and impaired the functional outcomes of rats at day 14 after MCAO [219]. Similarly, HMGB1 deprived of astrocytes was upregulated on day 14 after stroke, which promoted endothelial progenitor cell-mediated neurovascular remodeling [220]. Inhibition of HMGB1 with siRNA significantly reduced angiogenesis and worsened the neurological outcome [220]. Thus, targeting MMP-9 or HMGB1 with these compounds in a late phase may inhibit neurogenesis and angiogenesis, subsequently leading to unfavorable outcomes. Further investigations into the dynamic changes of $\mathrm{ONOO}^{-}, \mathrm{HMGB} 1$ and MMP-9 and their roles in different phases may help to predict the optimal therapy duration. Some studies observed the long- 
term protective effects. For example, Wang et al. [213] found that treatment with tanshinone IIA for 7 days or 14 days reduced the apoptosis in ischemic brains. However, they did not evaluate the optimal therapy duration. The optimal duration of treatment with these natural compounds should be determined by using different treatment durations with a relatively long observational period.

In addition to therapy duration and the time of outcome measurement, treatment dosage and dose-dependent responses should also be determined in further investigations. Although current studies have identified the dose-dependent response to these compounds, it is necessary to reevaluate the optimal dosage for a combination therapy with t-PA, as the outcome involves HT, which has not been investigated before. Potential drug-drug interactions of these compounds with t-PA should also be carefully examined in the development of combination therapy. To determine whether these compounds affect the thrombolytic effect of t-PA, it is necessary to adopt the thromboembolic model rather than the MCAO model for future studies [217].

\section{Conclusion}

ONOO-, HMGB1 and MMP-9 are important pathological factors in cerebral ischemiareperfusion injury. The interaction of $\mathrm{ONOO}^{-}, \mathrm{HMGB} 1$ and MMP-9 can form $\mathrm{ONOO}^{-} / \mathrm{HMGB}^{-} /$ MMP-9 signaling cascades, potentially mediating the delayed t-PA-induced HT. Natural compounds from Chinese medicine including baicalin, resveratrol, curcumin, apocynin, glycyrrhizin, caffeic acid and tanshinone IIA are promising drug candidates for alleviating t-PAmediated HT possibly via inhibiting the $\mathrm{ONOO}^{-} / \mathrm{HMGB} / \mathrm{MMP}-9$ signaling cascades in ischemic stroke. Further studies are warranted to evaluate these compounds as a combination therapy to reduce HT in ischemic stroke with t-PA treatment.

\section{Acknowledgements}

This work was supported by the Hong Kong General Research Fund (GRF No. 17102915 and No. 776512M), Research Grant Council, Hong Kong, SAR; a grant from the National Natural Science Foundation of China (No. 31270902), and the Seed Funding Programme for Basic Research, University of Hong Kong (No. 201411159208). We thank Ms. Yuanyuan Cheng for drawing the compound structures.

\section{Disclosure Statement}

The authors declare no conflict of interest.

\section{References}

1 Roger VL, Go AS, Lloyd-Jones DM, et al: Heart disease and stroke statistics - 2011 update: a report from the American Heart Association. Circulation 2011;123:e18-e209.

2 Raphaeli G, Mazighi M, Pereira VM, Turjman F, Striefler J: State-of-the-art endovascular treatment of acute ischemic stroke. Adv Tech Stand Neurosurg 2015;42:33-68.

3 Wahlgren N, Ahmed N, Davalos A, Ford GA, Grond M, Hacke W, Hennerici MG, Kaste M, Kuelkens S, Larrue V, Lees KR, Roine RO, Soinne L, Toni D, Vanhooren G; SITS-MOST Investigators: Thrombolysis with alteplase for acute ischaemic stroke in the Safe Implementation of Thrombolysis in Stroke-Monitoring Study (SITS-MOST): an observational study. Lancet 2007;369:275-282. 
4 Tissue plasminogen activator for acute ischemic stroke. The National Institute of Neurological Disorders and Stroke rt-PA Stroke Study Group. N Engl J Med 1995;333:1581-1587.

5 Hacke W, Kaste M, Bluhmki E, Brozman M, Davalos A, Guidetti D, Larrue V, Lees KR, Medeghri Z, Machnig T, Schneider D, von Kummer R, Wahlgren N, Toni D, Investigators E: Thrombolysis with alteplase 3-4.5 h after acute ischemic stroke. N Engl J Med 2008;359:1317-1329.

6 Lansberg MG, Bluhmki E, Thijs VN: Efficacy and safety of tissue plasminogen activator 3-4.5 h after acute ischemic stroke: a metaanalysis. Stroke 2009;40:2438-2441.

7 Hacke W, Donnan G, Fieschi C, Kaste M, et al: Association of outcome with early stroke treatment: pooled analysis of ATLANTIS, ECASS, and NINDS rt-PA stroke trials. Lancet 2004;363:768-774.

8 Cheng NT, Kim AS: Intravenous thrombolysis for acute ischemic stroke within 3 hours versus between 3 and 4.5 hours of symptom onset. Neurohospitalist 2015;5:101-109.

9 Khatri P, Wechsler LR, Broderick JP: Intracranial hemorrhage associated with revascularization therapies. Stroke 2007;38:431-440.

10 Ishrat T, Soliman S, Guan W, Saler M, Fagan SC: Vascular protection to increase the safety of tissue plasminogen activator for stroke. Curr Pharm Des 2012;18:3677-3684.

11 Yamashita T, Abe K: Therapeutic approaches to vascular protection in ischemic stroke. Acta Med Okayama 2011;65:219-223.

12 Chen HS, Chen XM, Feng JH, Liu KJ, Qi SH, Shen JG: Peroxynitrite decomposition catalyst reduces delayed thrombolysis-induced hemorrhagic transformation in ischemia-reperfused rat brains. CNS Neurosci Ther 2015;21:585-590.

13 Qiu J, Xu J, Zheng Y, Wei Y, Zhu X, Lo EH, Moskowitz MA, Sims JR: High-mobility group box 1 promotes metalloproteinase-9 upregulation through Toll-like receptor 4 after cerebral ischemia. Stroke 2010;41:2077-2082.

14 Yu Y, Tang D, Kang R: Oxidative stress-mediated HMGB1 biology. Front Physiol 2015;6:93.

15 Singh DP, Chopra K: Flavocoxid, dual inhibitor of cyclooxygenase-2 and 5-lipoxygenase, exhibits neuroprotection in rat model of ischaemic stroke. Pharmacol Biochem Behav 2014;120:33-42.

$16 \mathrm{Gu}$ Y, Chen J, Shen J: Herbal medicines for ischemic stroke: combating inflammation as therapeutic targets. J Neuroimmune Pharmacol 2014;9:313-339.

17 Ghosh N, Ghosh R, Bhat ZA, Mandal V, Bachar SC, Nima ND, Sunday 00, Mandal SC: Advances in herbal medicine for treatment of ischemic brain injury. Nat Prod Commun 2014;9:1045-1055.

18 Wang X, Tsuji K, Lee SR, Ning M, Furie KL, Buchan AM, Lo EH: Mechanisms of hemorrhagic transformation after tissue plasminogen activator reperfusion therapy for ischemic stroke. Stroke 2004;35:2726-2730.

19 Rosell A, Foerch C, Murata Y, Lo EH: Mechanisms and markers for hemorrhagic transformation after stroke. Acta Neurochir Suppl 2008;105:173-178.

20 Lapchak PA: Hemorrhagic transformation following ischemic stroke: significance, causes, and relationship to therapy and treatment. Curr Neurol Neurosci Rep 2002;2:38-43.

21 Hamann GF, del Zoppo GJ, von Kummer R: Hemorrhagic transformation of cerebral infarction - possible mechanisms. Thromb Haemost 1999;82(suppl 1):92-94.

22 Wang W, Li M, Chen Q, Wang J: Hemorrhagic transformation after tissue plasminogen activator reperfusion therapy for ischemic stroke: mechanisms, models, and biomarkers. Mol Neurobiol 2015;52:1572-1579.

23 Jickling GC, Liu D, Stamova B, Ander BP, Zhan X, Lu A, Sharp FR: Hemorrhagic transformation after ischemic stroke in animals and humans. J Cereb Blood Flow Metab 2014;34:185-199.

24 Chaturvedi M, Kaczmarek L: Mmp-9 inhibition: a therapeutic strategy in ischemic stroke. Mol Neurobiol 2014; 49:563-573.

25 Chen XM, Chen HS, Xu MJ, Shen JG: Targeting reactive nitrogen species: a promising therapeutic strategy for cerebral ischemia-reperfusion injury. Acta Pharmacol Sin 2013;34:67-77.

26 Suzuki M, Tabuchi M, Ikeda M, Tomita T: Concurrent formation of peroxynitrite with the expression of inducible nitric oxide synthase in the brain during middle cerebral artery occlusion and reperfusion in rats. Brain Res 2002;951:113-120.

27 Kuhn DM, Sakowski SA, Sadidi M, Geddes TJ: Nitrotyrosine as a marker for peroxynitrite-induced neurotoxicity: the beginning or the end of the end of dopamine neurons? J Neurochem 2004;89:529-536.

28 Takizawa S, Fukuyama N, Hirabayashi H, Nakazawa H, Shinohara Y: Dynamics of nitrotyrosine formation and decay in rat brain during focal ischemia-reperfusion. J Cereb Blood Flow Metab 1999;19:667-672.

29 Bas DF, Topcuoglu MA, Gursoy-Ozdemir Y, Saatci I, Bodur E, Dalkara T: Plasma 3-nitrotyrosine estimates the reperfusion-induced cerebrovascular stress, whereas matrix metalloproteinases mainly reflect plasma activity: a study in patients treated with thrombolysis or endovascular recanalization. J Neurochem 2012; 123(suppl 2):138-147.

30 Crow JP, Beckman JS: The role of peroxynitrite in nitric oxide-mediated toxicity. Curr Top Microbiol Immunol 1995;196:57-73.

31 Groves JT: Peroxynitrite: reactive, invasive and enigmatic. Curr Opin Chem Biol 1999;3:226-235.

32 Lizasoain I, Moro M, Knowles R, Darley-Usmar V, Moncada S: Nitric oxide and peroxynitrite exert distinct effects on mitochondrial respiration which are differentially blocked by glutathione or glucose. Biochem J 1996;314:877-880.

33 Vieira HL, Belzacq AS, Haouzi D, Bernassola F, Cohen I, Jacotot E, Ferri KF, El Hamel C, Bartle LM, Melino G, Brenner C, Goldmacher V, Kroemer G: The adenine nucleotide translocator: a target of nitric oxide, peroxynitrite, and 4-hydroxynonenal. Oncogene 2001;20:4305-4316. 
34 Salgo MG, Squadrito GL, Pryor WA: Peroxynitrite causes apoptosis in rat thymocytes. Biochem Biophys Res Commun 1995;215:1111-1118.

35 Tajes M, Ill-Raga G, Palomer E, Ramos-Fernandez E, et al: Nitro-oxidative stress after neuronal ischemia induces protein nitrotyrosination and cell death. Oxid Med Cell Longev 2013;2013:826143.

36 Radi R, Beckman JS, Bush KM, Freeman BA: Peroxynitrite-induced membrane lipid peroxidation: the cytotoxic potential of superoxide and nitric oxide. Arch Biochem Biophys 1991;288:481-487.

37 Virág L, Szabó É, Gergely P, Szabó C: Peroxynitrite-induced cytotoxicity: mechanism and opportunities for intervention. Toxicol Lett 2003;140:113-124.

38 Brzezinska AK, Gebremedhin D, Chilian WM, Kalyanaraman B, Elliott SJ: Peroxynitrite reversibly inhibits $\mathrm{Ca}^{2+}$ activated $\mathrm{K}^{+}$channels in rat cerebral artery smooth muscle cells. Am J Physiol Heart Circ Physiol 2000; 278:H1883-H1890.

39 Zanelli SA, Ashraf QM, Delivoria-Papadopoulos M, Mishra OP: Peroxynitrite-induced modification of the N-methyl-D-aspartate receptor in the cerebral cortex of the guinea pig fetus at term. Neurosci Lett 2000;296:5-8.

40 Dhar A, Kaundal RK, Sharma SS: Neuroprotective effects of FeTMPyP: a peroxynitrite decomposition catalyst in global cerebral ischemia model in gerbils. Pharmacol Res 2006;54:311-316.

41 Thiyagarajan M, Kaul CL, Sharma SS: Neuroprotective efficacy and therapeutic time window of peroxynitrite decomposition catalysts in focal cerebral ischemia in rats. Br J Pharmacol 2004;142:899-911.

42 Li R, Huang C, Chen J, Guo Y, Tan S: The role of uric acid as a potential neuroprotectant in acute ischemic stroke: a review of literature. Neurol Sci 2015;36:1097-1103.

43 Yu ZF, Bruce-Keller AJ, Goodman Y, Mattson MP: Uric acid protects neurons against excitotoxic and metabolic insults in cell culture, and against focal ischemic brain injury in vivo. J Neurosci Res 1998;53:613-625.

44 Romanos E, Planas AM, Amaro S, Chamorro Á: Uric acid reduces brain damage and improves the benefits of rt-PA in a rat model of thromboembolic stroke. Cereb Blood Flow Metab 2007;27:14-20.

45 Wang Z, Lin Y, Liu Y, Chen Y, Wang B, Li C, Yan S, Wang Y, Zhao W: Serum uric acid levels and outcomes after acute ischemic stroke. Mol Neurobiol 2015, Epub ahead of print.

46 Nagase H, Woessner JF Jr: Matrix metalloproteinases. J Biol Chem 1999;274:21491-21494.

47 Bauer AT, Burgers HF, Rabie T, Marti HH: Matrix metalloproteinase-9 mediates hypoxia-induced vascular leakage in the brain via tight junction rearrangement. J Cereb Blood Flow Metab 2010;30:837-848.

48 Yamada H, Yoneda M, Inaguma S, Watanabe D, Banno S, Yoshikawa K, Mizutani K, Iwaki M, Zako M: Infliximab counteracts tumor necrosis factor-alpha-enhanced induction of matrix metalloproteinases that degrade claudin and occludin in non-pigmented ciliary epithelium. Biochem Pharmacol 2013;85:1770-1782.

49 Yang Y, Estrada EY, Thompson JF, Liu W, Rosenberg GA: Matrix metalloproteinase-mediated disruption of tight junction proteins in cerebral vessels is reversed by synthetic matrix metalloproteinase inhibitor in focal ischemia in rat. J Cereb Blood Flow Metab 2007;27:697-709.

50 Rosell A, Cuadrado E, Ortega-Aznar A, Hernandez-Guillamon M, Lo EH, Montaner J: MMP-9-positive neutrophil infiltration is associated to blood-brain barrier breakdown and basal lamina type IV collagen degradation during hemorrhagic transformation after human ischemic stroke. Stroke 2008;39:1121-1126.

51 Gidday JM, Gasche YG, Copin JC, Shah AR, Perez RS, Shapiro SD, Chan PH, Park TS: Leukocyte-derived matrix metalloproteinase-9 mediates blood-brain barrier breakdown and is proinflammatory after transient focal cerebral ischemia. Am J Physiol Heart Circ Physiol 2005;289:H558-H568.

52 Lakhan SE, Kirchgessner A, Tepper D, Leonard A: Matrix metalloproteinases and blood-brain barrier disruption in acute ischemic stroke. Front Neurol 2013;432.

53 Clark AW, Krekoski CA, Bou SS, Chapman KR, Edwards DR: Increased gelatinase A (MMP-2) and gelatinase B (MMP-9) activities in human brain after focal ischemia. Neurosci Lett 1997;238:53-56.

54 Rosell A, Ortega-Aznar A, Alvarez-Sabín J, Fernández-Cadenas I, Ribó M, Molina CA, Lo EH, Montaner J: Increased brain expression of matrix metalloproteinase- 9 after ischemic and hemorrhagic human stroke. Stroke 2006;37:1399-1406.

55 Lee SR, Tsuji K, Lee SR, Lo EH: Role of matrix metalloproteinases in delayed neuronal damage after transient global cerebral ischemia. J Neurosci 2004;24:671-678.

56 Gu Z, Cui J, Brown S, Fridman R, Mobashery S, Strongin AY, Lipton SA: A highly specific inhibitor of matrix metalloproteinase- 9 rescues laminin from proteolysis and neurons from apoptosis in transient focal cerebral ischemia. J Neurosci 2005;25:6401-6408.

57 Romanic AM, White RF, Arleth AJ, Ohlstein EH, Barone FC: Matrix metalloproteinase expression increases after cerebral focal ischemia in rats inhibition of matrix metalloproteinase-9 reduces infarct size. Stroke 1998;29: 1020-1030.

58 Asahi M, Wang X, Mori T, Sumii T, Jung JC, Moskowitz MA, Fini ME, Lo EH: Effects of matrix metalloproteinase-9 gene knock-out on the proteolysis of blood-brain barrier and white matter components after cerebral ischemia. J Neurosci 2001;21:7724-7732.

59 Yang Y, Rosenberg GA: Matrix metalloproteinases as therapeutic targets for stroke. Brain Res 2015;1623: 30-38.

60 Hu Q, Chen C, Yan J, Yang X, Shi X, Zhao J, Lei J, Yang L, Wang K, Chen L: Therapeutic application of gene silencing MMP-9 in a middle cerebral artery occlusion-induced focal ischemia rat model. Exp Neurol 2009;216:35-46.

61 Hu Q, Chen C, Khatibi NH, Li L, Yang L, Wang K, Han J, Duan W, Zhang JH, Zhou C: Lentivirus-mediated transfer of MMP-9 shRNA provides neuroprotection following focal ischemic brain injury in rats. Brain Res 2011;1367: 347-359. 
Chen et al.: Targeting ONOO-/HMGB1/MMP-9 Signaling Cascades

62 Rosenberg G, Estrada E, Dencoff J: Matrix metalloproteinases and TIMPs are associated with blood-brain barrier opening after reperfusion in rat brain. Stroke 1998;29:2189-2195.

63 Cuadrado E, Ortega L, Hernandez-Guillamon M, Penalba A, Fernandez-Cadenas I, Rosell A, Montaner J: Tissue plasminogen activator (t-PA) promotes neutrophil degranulation and MMP-9 release. J Leukoc Biol 2008;84: 207-214.

64 Sumii T, Lo EH: Involvement of matrix metalloproteinase in thrombolysis-associated hemorrhagic transformation after embolic focal ischemia in rats. Stroke 2002;33:831-836.

65 Tsuji K, Aoki T, Tejima E, Arai K, Lee SR, Atochin DN, Huang PL, Wang X, Montaner J, Lo EH: Tissue plasminogen activator promotes matrix metalloproteinase-9 upregulation after focal cerebral ischemia. Stroke 2005;36: 1954-1959.

66 Pfefferkorn T, Rosenberg GA: Closure of the blood-brain barrier by matrix metalloproteinase inhibition reduces rtPA-mediated mortality in cerebral ischemia with delayed reperfusion. Stroke 2003;34:2025-2030.

67 Fujimoto M, Takagi Y, Aoki T, Hayase M, Marumo T, Gomi M, Nishimura M, Kataoka H, Hashimoto N, Nozaki K: Tissue inhibitor of metalloproteinases protect blood-brain barrier disruption in focal cerebral ischemia. J Cereb Blood Flow Metab 2008;28:1674-1685.

68 Lapchak PA, Chapman DF, Zivin JA: Metalloproteinase inhibition reduces thrombolytic (tissue plasminogen activator)-induced hemorrhage after thromboembolic stroke. Stroke 2000;31:3034-3040.

69 Mishiro K, Ishiguro M, Suzuki Y, Tsuruma K, Shimazawa M, Hara H: A broad-spectrum matrix metalloproteinase inhibitor prevents hemorrhagic complications induced by tissue plasminogen activator in mice. Neuroscience 2012;205:39-48.

70 Ramos-Fernandez M, Bellolio MF, Stead LG: Matrix metalloproteinase-9 as a marker for acute ischemic stroke: a systematic review. J Stroke Cerebrovasc Dis 2011;20:47-54.

71 Montaner J, Molina CA, Monasterio J, Abilleira S, Arenillas JF, Ribo M, Quintana M, Alvarez-Sabin J: Matrix metalloproteinase-9 pretreatment level predicts intracranial hemorrhagic complications after thrombolysis in human stroke. Circulation 2003;107:598-603.

72 Andersson U, Tracey KJ: HMGB1 is a therapeutic target for sterile inflammation and infection. Annu Rev Immunol 2011;29:139-162.

73 Landsman D, Bustin M: A signature for the HMG-1 box DNA-binding proteins. Bioessays 1993;15:539-546.

74 Bianchi ME, Agresti A: HMG proteins: dynamic players in gene regulation and differentiation. Curr Opin Genet Dev 2005;15:496-506.

75 Qiu J, Nishimura M, Wang Y, Sims JR, Qiu S, Savitz SI, Salomone S, Moskowitz MA: Early release of HMGB-1 from neurons after the onset of brain ischemia. J Cereb Blood Flow Metab 2008;28:927-938.

76 Scaffidi P, Misteli T, Bianchi ME: Release of chromatin protein HMGB1 by necrotic cells triggers inflammation. Nature 2002;418:191-195.

77 Bonaldi T, Talamo F, Scaffidi P, Ferrera D, Porto A, Bachi A, Rubartelli A, Agresti A, Bianchi ME: Monocytic cells hyperacetylate chromatin protein HMGB1 to redirect it towards secretion. EMBO J 2003;22:5551-5560.

78 Tang D, Shi Y, Kang R, Li T, Xiao W, Wang H, Xiao X: Hydrogen peroxide stimulates macrophages andmonocytes to actively release HMGB1. J Leukoc Biol 2007;81:741-747.

79 Oh YJ, Youn JH, Ji Y, Lee SE, Lim KJ, Choi JE, Shin JS: HMGB1 is phosphorylated by classical protein kinase C and is secreted by a calcium-dependent mechanism. J Immunol 2009;182:5800-5809.

80 Hoppe G, Talcott KE, Bhattacharya SK, Crabb JW, Sears JE: Molecular basis for the redox control of nuclear transport of the structural chromatin protein Hmgb1. Exp Cell Res 2006;312:3526-3538.

81 Yang QW, Wang JZ, Li JC, Zhou Y, Zhong Q, Lu FL, Xiang J: High-mobility group protein box-1 and its relevance to cerebral ischemia. J Cereb Blood Flow Metab 2010;30:243-254.

82 Zhang J, Takahashi HK, Liu K, Wake H, Liu R, Maruo T, Date I, Yoshino T, Ohtsuka A, Mori S, Nishibori M: Antihigh mobility group box-1 monoclonal antibody protects the blood-brain barrier from ischemia-induced disruption in rats. Stroke 2011;42:1420-1428.

83 Lei C, Lin S, Zhang C, Tao W, Dong W, Hao Z, Liu M, Wu B: High-mobility group box1 protein promotes neuroinflammation after intracerebral hemorrhage in rats. Neuroscience 2013;228:190-199.

84 Gong G, Xiang L, Yuan L, Hu L, Wu W, Cai L, Yin L, Dong H: Protective effect of glycyrrhizin, a direct HMGB1 inhibitor, on focal cerebral ischemia/reperfusion-induced inflammation, oxidative stress, and apoptosis in rats. PLoS One 2014;9:e89450.

85 Ohnishi M, Katsuki H, Fukutomi C, Takahashi M, Motomura M, Fukunaga M, Matsuoka Y, Isohama Y, Izumi Y, Kume T, Inoue A, Akaike A: HMGB1 inhibitor glycyrrhizin attenuates intracerebral hemorrhage-induced injury in rats. Neuropharmacology 2011;61:975-980.

86 Roussel BD, Mysiorek C, Rouhiainen A, Jullienne A, Parcq J, Hommet Y, Culot M, Berezowski V, Cecchelli R, Rauvala H, Vivien D, Ali C: HMGB-1 promotes fibrinolysis and reduces neurotoxicity mediated by tissue plasminogen activator. J Cell Sci 2011;124:2070-2076.

87 Gürsoy-Özdemir Y, Can A, Dalkara T: Reperfusion-induced oxidative/nitrative injury to neurovascular unit after focal cerebral ischemia. Stroke 2004;35:1449-1453.

88 Gu Y, Zheng G, Xu M, Li Y, Chen X, Zhu W, Tong Y, Chung SK, Liu KJ, Shen J: Caveolin-1 regulates nitric oxidemediated matrix metalloproteinases activity and blood-brain barrier permeability in focal cerebral ischemia and reperfusion injury. J Neurochem 2012;120:147-156.

89 Tan KH, Harrington S, Purcell WM, Hurst RD: Peroxynitrite mediates nitric oxide-induced blood-brain barrier damage. Neurochem Res 2004;29:579-587. 
90 Bond M, Fabunmi RP, Baker AH, Newby AC: Synergistic upregulation of metalloproteinase-9 by growth factors and inflammatory cytokines: an absolute requirement for transcription factor NF-kappa B. FEBS Lett 1998; 435:29-34.

91 Okamoto T, Akaike T, Sawa T, Miyamoto Y, van der Vliet A, Maeda H: Activation of matrix metalloproteinases by peroxynitrite-induced protein S-glutathiolation via disulfide S-oxide formation. J Biol Chem 2001;276: 29596-29602.

92 Suofu Y, Clark J, Broderick J, Wagner KR, Tomsick T, Sa Y, Lu A: Peroxynitrite decomposition catalyst prevents MMP activation and neurovascular injury after prolonged cerebral ischemia in rats. J Neurochem 2010;115: 1266.

93 Ding R, Feng L, He L, Chen Y, Wen P, Fu Z, Lin C, Yang S, Deng X, Zeng J, Sun G: Peroxynitrite decomposition catalyst prevents matrix metalloproteinase- 9 activation and neurovascular injury after hemoglobin injection into the caudate nucleus of rats. Neuroscience 2015;297:182-193.

94 Ding R, Chen Y, Yang S, Deng X, Fu Z, Feng L, Cai Y, Du M, Zhou Y, Tang Y: Blood-brain barrier disruption induced by hemoglobin in vivo: involvement of up-regulation of nitric oxide synthase and peroxynitrite formation. Brain Res 2014;1571:25-38.

95 Amaro S, Obach V, Cervera A, Urra X, Gomez-Choco M, Planas AM, Chamorro A: Course of matrix metalloproteinase- 9 isoforms after the administration of uric acid in patients with acute stroke: a proof-of-concept study. J Neurol 2009;256:651-656.

96 Janko C, Filipovic M, Munoz LE, Schorn C, Schett G, Ivanovic-Burmazovic I, Herrmann M: Redox modulation of HMGB1-related signaling. Antioxid Redox Signal 2014;20:1075-1085.

97 Kikuchi K, Kawahara KI, Tancharoen S, Matsuda F, Morimoto Y, Ito T, Biswas KK, Takenouchi K, Miura N, Oyama Y: The free radical scavenger edaravone rescues rats from cerebral infarction by attenuating the release of high-mobility group box-1 in neuronal cells. J Pharmacol Exp Therapeut 2009;329:865-874.

98 Wang H, Liu D: Baicalin inhibits high-mobility group box 1 release and improves survival in experimental sepsis. Shock 2014;41:324-330.

99 Loukili N, Rosenblatt-Velin N, Li J, Clerc S, Pacher P, Feihl F, Waeber B, Liaudet L: Peroxynitrite induces HMGB1 release by cardiac cells in vitro and HMGB1 upregulation in the infarcted myocardium in vivo. Cardiovasc Res 2011;89:586-594.

100 Rabadi MM, Kuo M-C, Ghaly T, Rabadi SM, Weber M, Goligorsky MS, Ratliff BB: Interaction between uric acid and HMGB1 translocation and release from endothelial cells. Am J Physiol Renal Physiol 2012;302:F730F741.

101 Sapojnikova N, Kartvelishvili T, Asatiani N, Zinkevich V, Kalandadze I, Gugutsidze D, Shakarishvili R, Tsiskaridze A: Correlation between MMP-9 and extracellular cytokine HMGB1 in prediction of human ischemic stroke outcome. Biochim Biophys Acta 2014;1842:1379-1384.

102 Zhou S, Xiao P: A Modern Practical Handbook of Neurology and Psychosis of the Integration of Traditional Chinese and Western Medicine. Changsha, Hunan Science and Technology Publisher, 1997, p 633.

103 Liu Z, Zhang Y, Liu J: Traditional Chinese medicine for stroke: an overview of systematic reviews. J Altern Complement Med 2014;20:A140-A140.

104 Sucher NJ: The application of Chinese medicine to novel drug discovery. Expert Opin Drug Discov 2013;8: 21-34.

105 Sucher NJ, Carles MC: Chinese herbal medicines for neuroprotection in ischemic stroke: promise and reality; in Wagner H, Ulrich-Merzenich G (eds): Evidence and Rational Based Research on Chinese Drugs. Berlin, Springer, 2013, pp 363-395.

106 Shang X, He X, He X, Li M, Zhang R, Fan P, Zhang Q, Jia Z: The genus Scutellaria an ethnopharmacological and phytochemical review. J Ethnopharmacol 2010;128:279-313.

107 Li H, Zhang Y, Yu Y, Li B, Chen Y, Wu H, Wang J, Li J, Xiong X, He Q, Tian J, Wang Z, Wang J: Systemic revealing pharmacological signalling pathway networks in the hippocampus of ischaemia-reperfusion mice treated with baicalin. Evid Based Complement Alternat Med 2013;2013:630723.

108 Xu M, Chen X, Gu Y, Peng T, Yang D, Chang RC, So KF, Liu K, Shen J: Baicalin can scavenge peroxynitrite and ameliorate endogenous peroxynitrite-mediated neurotoxicity in cerebral ischemia-reperfusion injury. J Ethnopharmacol 2013;150:116-124.

109 Tu XK, Yang WZ, Shi SS, Chen Y, Wang CH, Chen CM, Chen Z: Baicalin inhibits TLR2/4 signaling pathway in rat brain following permanent cerebral ischemia. Inflammation 2011;34:463-470.

110 Xue X, Qu XJ, Yang Y, Sheng XH, Cheng F, Jiang EN, Wang JH, Bu W, Liu ZP: Baicalin attenuates focal cerebral ischemic reperfusion injury through inhibition of nuclear factor kappaB p65 activation. Biochem Biophys Res Commun 2010;403:398-404.

111 Ge QF, Hu X, Ma ZQ, Liu JR, Zhang WP, Chen Z, Wei EQ: Baicalin attenuates oxygen-glucose deprivation-induced injury via inhibiting NMDA receptor-mediated 5-lipoxygenase activation in rat cortical neurons. Pharmacol Res 2007;55:148-157.

112 Cheng O, Li Z, Han Y, Jiang Q, Yan Y, Cheng K: Baicalin improved the spatial learning ability of global ischemia/ reperfusion rats by reducing hippocampal apoptosis. Brain Res 2012;1470:111-118.

113 Zhou QB, Duan CZ, Jia Q, Liu P, Li LY: Baicalin attenuates focal cerebral ischemic reperfusion injury by inhibition of protease-activated receptor-1 and apoptosis. Chin J Integr Med 2014;20:116-122.

114 Zhou QB, Jia Q, Zhang Y, Li LY, Chi ZF, Liu P: Effects of baicalin on protease-activated receptor-1 expression and brain injury in a rat model of intracerebral hemorrhage. Chin J Physiol 2012;55:202-209. 
115 Kim DH, Cho KH, Moon SK, Kim YS, Kim DH, Choi JS, Chung HY: Cytoprotective mechanism of baicalin against endothelial cell damage by peroxynitrite. J Pharm Pharmacol 2005;57:1581-1590.

116 Tu XK, Yang WZ, Liang RS, Shi SS, Chen JP, Chen CM, Wang CH, Xie HS, Chen Y, Ouyang LQ: Effect of baicalin on matrix metalloproteinase- 9 expression and blood-brain barrier permeability following focal cerebral ischemia in rats. Neurochem Res 2011;36:2022-2028.

117 Zhou QB, Jin YL, Jia Q, Zhang Y, Li LY, Liu P, Liu YT: Baicalin attenuates brain edema in a rat model of intracerebral hemorrhage. Inflammation 2014;37:107-115.

118 Wang XF, Zhou QM, Du J, Zhang H, Lu YY, Su SB: Baicalin suppresses migration, invasion and metastasis of breast cancer via p38MAPK signaling pathway. Anticancer Agents Med Chem 2013;13:923-931.

119 Kwak S, Ku SK, Han MS, Bae JS: Vascular barrier protective effects of baicalin, baicalein and wogonin in vitro and in vivo. Toxicol Appl Pharmacol 2014;281:30-38.

120 Li L, Bao H, Wu J, Duan X, Liu B, Sun J, Gong W, Lv Y, Zhang H, Luo Q, Wu X, Dong J: Baicalin is anti-inflammatory in cigarette smoke-induced inflammatory models in vivo and in vitro: a possible role for HDAC2 activity. Int Immunopharmacol 2012;13:15-22.

121 He M, Zhang B, Wei X, Wang Z, Fan B, Du P, Zhang Y, Jian W, Chen L, Wang L: HDAC4/5-HMGB1 signalling mediated by NADPH oxidase activity contributes to cerebral ischaemia/reperfusion injury. J Cell Mol Med 2013;17:531-542.

122 Zou JY, Crews FT: Release of neuronal HMGB1 by ethanol through decreased HDAC activity activates brain neuroimmune signaling. PLoS One 2014;9:e87915.

123 Liu LY, Wei EQ, Zhao YM, Chen FX, Wang ML, Zhang WP, Chen Z: Protective effects of baicalin on oxygen/ glucose deprivation- and NMDA-induced injuries in rat hippocampal slices. J Pharm Pharmacol 2005;57: 1019-1026.

124 Zhu H, Wang Z, Xing Y, Gao Y, Ma T, Lou L, Lou J, Gao Y, Wang S, Wang Y: Baicalin reduces the permeability of the blood-brain barrier during hypoxia in vitro by increasing the expression of tight junction proteins in brain microvascular endothelial cells. J Ethnopharmacol 2012;141:714-720.

125 Gao L, Chu Q, Ye J: Determination of trans-resveratrol in wines, herbs and health food by capillary electrophoresis with electrochemical detection. Food Chem 2002;78:255-260.

126 Nabavi SF, Li H, Daglia M, Nabavi SM: Resveratrol and stroke: from chemistry to medicine. Curr Neurovasc Res 2014;11:390-397.

127 Huang T, Gao D, Jiang X, Hu S, Zhang L, Fei Z: Resveratrol inhibits oxygen-glucose deprivation-induced MMP-3 expression and cell apoptosis in primary cortical cells via the NF-kappaB pathway. Mol Med Rep 2014;10: 1065-1071.

128 Li Z, Pang L, Fang F, Zhang G, Zhang J, Xie M, Wang L: Resveratrol attenuates brain damage in a rat model of focal cerebral ischemia via up-regulation of hippocampal Bcl-2. Brain Res 2012;1450:116-124.

129 Yousuf S, Atif F, Ahmad M, Hoda N, Ishrat T, Khan B, Islam F: Resveratrol exerts its neuroprotective effect by modulating mitochondrial dysfunctions and associated cell death during cerebral ischemia. Brain Res 2009; 1250:242-253

130 Shin JA, Lee H, Lim YK, Koh Y, Choi JH, Park EM: Therapeutic effects of resveratrol during acute periods following experimental ischemic stroke. J Neuroimmunol 2010;227:93-100.

131 Lopez MS, Dempsey RJ, Vemuganti R: Resveratrol neuroprotection in stroke and traumatic CNS injury. Neurochem Int 2015;89:75-82.

132 Li C, Yan Z, Yang J, Chen H, Li H, Jiang Y, Zhang Z: Neuroprotective effects of resveratrol on ischemic injury mediated by modulating the release of neurotransmitter and neuromodulator in rats. Neurochem Int 2010; 56:495-500.

133 Shah FA, Gim SA, Kim MO, Koh P0: Proteomic identification of proteins differentially expressed in response to resveratrol treatment in middle cerebral artery occlusion stroke model. J Vet Med Sci 2014;76:1367-1374.

134 Koronowski KB, Dave KR, Saul I, Camarena V, Thompson JW, Neumann JT, Young JI, Perez-Pinzon MA: Resveratrol preconditioning induces a novel extended window of ischemic tolerance in the mouse brain. Stroke 2015;46:2293-2298.

135 Narayanan SV, Dave KR, Saul I, Perez-Pinzon MA: Resveratrol preconditioning protects against cerebral ischemic injury via nuclear erythroid 2-related factor 2. Stroke 2015;46:1626-1632.

136 Ren J, Fan C, Chen N, Huang J, Yang Q: Resveratrol pretreatment attenuates cerebral ischemic injury by upregulating expression of transcription factor Nrf2 and HO-1 in rats. Neurochem Res 2011;36:2352-2362.

137 Wang LM, Wang YJ, Cui M, Luo WJ, Wang XJ, Barber PA, Chen ZY: A dietary polyphenol resveratrol acts to provide neuroprotection in recurrent stroke models by regulating AMPK and SIRT1 signaling, thereby reducing energy requirements during ischemia. Eur J Neurosci 2013;37:1669-1681.

138 Clark D, Tuor UI, Thompson R, Institoris A, Kulynych A, Zhang X, Kinniburgh DW, Bari F, Busija DW, Barber PA: Protection against recurrent stroke with resveratrol: endothelial protection. PLoS One 2012;7:e47792.

139 Du K, McGill MR, Xie Y, Bajt ML, Jaeschke H: Resveratrol prevents protein nitration and release of endonucleases from mitochondria during acetaminophen hepatotoxicity. Food Chem Toxicol 2015;81:62-70.

140 Zhang HX, Duan GL, Wang CN, Zhang YQ, Zhu XY, Liu YJ: Protective effect of resveratrol against endotoxemiainduced lung injury involves the reduction of oxidative/nitrative stress. Pulm Pharmacol Ther 2014;27:150-155.

141 Yang M, Camara AK, Wakim BT, Zhou Y, Gadicherla AK, Kwok WM, Stowe DF: Tyrosine nitration of voltagedependent anion channels in cardiac ischemia-reperfusion: reduction by peroxynitrite scavenging. Biochim Biophys Acta 2012;1817:2049-2059. 
142 Holthoff JH, Woodling KA, Doerge DR, Burns ST, Hinson JA,Mayeux PR: Resveratrol, a dietary polyphenolic phytoalexin, is a functional scavenger of peroxynitrite. Biochem Pharmacol 2010;80:1260-1265.

143 Tsai SK, Hung LM, Fu YT, Cheng H, Nien MW, Liu HY, Zhang FB, Huang SS: Resveratrol neuroprotective effects during focal cerebral ischemia injury via nitric oxide mechanism in rats. J Vasc Surg 2007;46:346-353.

144 Bi XL, Yang JY, Dong YX, Wang JM, Cui YH, Ikeshima T, Zhao YQ, Wu CF: Resveratrol inhibits nitric oxide and TNF- $\alpha$ production by lipopolysaccharide-activated microglia. Int Immunopharmacol 2005;5:185-193.

145 Wei H, Wang S, Zhen L, Yang Q, Wu Z, Lei X, Lv J, Xiong L, Xue R: Resveratrol attenuates the blood-brain barrier dysfunction by regulation of the MMP-9/TIMP-1 balance after cerebral ischemia reperfusion in rats. J Mol Neurosci 2015;55:872-879.

146 Gao D, Zhang X, Jiang X, Peng Y, Huang W, Cheng G, Song L: Resveratrol reduces the elevated level of MMP-9 induced by cerebral ischemia-reperfusion in mice. Life Sci 2006;78:2564-2570.

147 Pandey AK, Bhattacharya P, Shukla SC, Paul S, Patnaik R: Resveratrol inhibits matrix metalloproteinases to attenuate neuronal damage in cerebral ischemia: a molecular docking study exploring possible neuroprotection. Neural Regen Res 2015;10:568-575.

148 Gao D, Huang T, Jiang X, Hu S, Zhang L, Fei Z: Resveratrol protects primary cortical neuron cultures from transient oxygen-glucose deprivation by inhibiting MMP-9. Mol Med Rep 2014;9:2197-2204.

149 Cheng G, Zhang X, Gao D, Jiang X, Dong W: Resveratrol inhibits MMP-9 expression by up-regulating PPAR alpha expression in an oxygen glucose deprivation-exposed neuron model. Neurosci Lett 2009;451:105-108.

150 Dong WW, Liu YJ, Lv Z, Mao YF, Wang YW, Zhu XY, Jiang L: Lung endothelial barrier protection by resveratrol involves inhibition of HMGB1 release and HMGB1-induced mitochondrial oxidative damage via an Nrf2dependent mechanism. Free Radic Biol Med 2015;88:404-416.

151 Ma C, Wang Y, Dong L, Li M, Cai W: Anti-inflammatory effect of resveratrol through the suppression of NF-kappaB and JAK/STAT signaling pathways. Acta Biochim Biophys Sin (Shanghai) 2015;47:207-213.

152 Lu B, Antoine DJ, Kwan K, Lundback P, Wahamaa H, Schierbeck H, Robinson M, Van Zoelen MA, Yang H, Li J, Erlandsson-Harris H, Chavan SS, Wang H, Andersson U, Tracey KJ: JAK/STAT1 signaling promotes HMGB1 hyperacetylation and nuclear translocation. Proc Natl Acad Sci USA 2014;111:3068-3073.

153 Rabadi MM, Xavier S, Vasko R, Kaur K, Goligorksy MS, Ratliff BB: High-mobility group box 1 is a novel deacetylation target of Sirtuin1. Kidney Int 2015;87:95-108.

154 Xu W, Lu Y, Yao J, Li Z, Chen Z, Wang G, Jing H, Zhang X, Li M, Peng J, Tian X: Novel role of resveratrol: suppression of high-mobility group protein box 1 nucleocytoplasmic translocation by the upregulation of sirtuin 1 in sepsis-induced liver injury. Shock 2014;42:440-447.

155 Karuppagounder V, Arumugam S, Thandavarayan RA, Pitchaimani V, Sreedhar R, Afrin R, Harima M, Suzuki H, Nomoto M, Miyashita S, Suzuki K, Watanabe K: Resveratrol attenuates HMGB1 signaling and inflammation in house dust mite-induced atopic dermatitis in mice. Int Immunopharmacol 2014;23:617-623.

156 Ni H, Jin W, Zhu T, Wang J, Yuan B, Jiang J, Liang W, Ma Z: Curcumin modulates TLR4/NF-кB inflammatory signaling pathway following traumatic spinal cord injury in rats. J Spinal Cord Med 2015;38:199-206.

157 Kelly-Cobbs AI, Prakash R, Li W, Pillai B, Hafez S, Coucha M, Johnson MH, Ogbi SN, Fagan SC, Ergul A: Targets of vascular protection in acute ischemic stroke differ in type 2 diabetes. Am J Physiol Heart Circ Physiol 2013; 304:H806-H815

158 Jiang J, Wang W, Sun YJ, Hu M, Li F, Zhu DY: Neuroprotective effect of curcumin on focal cerebral ischemic rats by preventing blood-brain barrier damage. Eur J Pharmacol 2007;561:54-62.

159 Dohare P, Garg P, Jain V, Nath C, Ray M: Dose dependence and therapeutic window for the neuroprotective effects of curcumin in thromboembolic model of rat. Behav Brain Res 2008;193:289-297.

160 Zhao J, Zhao Y, Zheng W, Lu Y, Feng G, Yu S: Neuroprotective effect of curcumin on transient focal cerebral ischemia in rats. Brain Res 2008;1229:224-232.

161 Zhao J, Yu S, Zheng W, Feng G, Luo G, Wang L, Zhao Y: Curcumin improves outcomes and attenuates focal cerebral ischemic injury via antiapoptotic mechanisms in rats. Neurochem Res 2010;35:374-379.

162 Wu J, Li Q, Wang X, Yu S, Li L, Wu X, Chen Y, Zhao J, Zhao Y: Neuroprotection by curcumin in ischemic brain injury involves the Akt/Nrf2 pathway. PLoS One 2013;8:e59843.

163 Yang C, Zhang X, Fan H, Liu Y: Curcumin upregulates transcription factor Nrf2, HO-1 expression and protects rat brains against focal ischemia. Brain Res 2009;1282:133-141.

164 Dai LY, Cheng BH, Li J: Effect of curcumin on cerebral ischemia-reperfusion injury in rats (in Chinese). Zhong Yao Cai 2015;38:344-349.

165 Yeh CH, Lin YM, Wu YC, Lin PJ: Inhibition of NF-kappa B activation can attenuate ischemia/reperfusioninduced contractility impairment via decreasing cardiomyocytic proinflammatory gene up-regulation and matrix metalloproteinase expression. J Cardiovasc Pharmacol 2005;45:301-309.

166 Thiyagarajan M, Sharma SS: Neuroprotective effect of curcumin in middle cerebral artery occlusion induced focal cerebral ischemia in rats. Life Sci 2004;74:969-985.

167 Liu W, Fan Z, Han Y, Lu S, Zhang D, Bai X, Xu W, Li J, Wang H: Curcumin attenuates peroxynitrite-induced neurotoxicity in spiral ganglion neurons. Neurotoxicology 2011;32:150-157.

168 Iwunze MO, McEwan D: Peroxynitrite interaction with curcumin solubilized in ethanolic solution. Cell Mol Biol (Noisy-le-grand) 2004;50:749-752.

169 Huang S, Wang B, Zhang ZQ, Meng ZY, Cao H, Lian QQ, Li J: Effect of curcumin on the expression of high mobility group box 1 and apoptotic neurons in hippocampus after global cerebral ischemia reperfusion in rats (in Chinese). Zhonghua Yi Xue Za Zhi 2011;91:1340-1343. 
170 Kim YS, Kwon JS, Cho YK, Jeong MH, Cho JG, Park JC, Kang JC, Ahn Y: Curcumin reduces the cardiac ischemia-reperfusion injury: involvement of the toll-like receptor 2 in cardiomyocytes. J Nutr Biochem 2012;23:1514-1523.

$171 \mathrm{Gu}$ Q, Guan H, Shi Q, Zhang Y, Yang H: Curcumin attenuated acute Propionibacterium acnes-induced liver injury through inhibition of HMGB1 expression in mice. Int Immunopharmacol 2015;24:159-165.

172 't Hart BA, Copray S, Philippens I: Apocynin, a low molecular oral treatment for neurodegenerative disease. Biomed Res Int 2014;2014:298020.

173 Tang LL, Ye K, Yang XF, Zheng JS: Apocynin attenuates cerebral infarction after transient focal ischaemia in rats. J Int Med Res 2007;35:517-522.

174 Chen H, Song YS, Chan PH: Inhibition of NADPH oxidase is neuroprotective after ischemia-reperfusion. J Cereb Blood Flow Metab 2009;29:1262-1272.

175 Tang X, Zhong W, Tu Q, Ding B: NADPH oxidase mediates the expression of MMP-9 in cerebral tissue after ischemia-reperfusion damage. Neurol Res 2014;36:118-125.

176 Shao B, Bayraktutan U: Hyperglycaemia promotes cerebral barrier dysfunction through activation of protein kinase C-beta. Diabetes Obes Metab 2013;15:993-999.

177 Won SJ, Tang XN, Suh SW, Yenari MA, Swanson RA: Hyperglycemia promotes tissue plasminogen activatorinduced hemorrhage by increasing superoxide production. Ann Neurol 2011;70:583-590.

178 He M, Zhang B, Wei X, Wang Z, Fan B, Du P, Zhang Y, Jian W, Chen L, Wang L, Fang H, Li X, Wang PA, Yi F: HDAC4/5-HMGB1 signalling mediated by NADPH oxidase activity contributes to cerebral ischaemia/reperfusion injury. J Cell Mol Med 2013;17:531-542.

179 Wang X, Chu G, Yang Z, Sun Y, Zhou H, Li M, Shi J, Tian B, Zhang C, Meng X: Ethanol directly induced HMGB1 release through NOX2/NLRP1 inflammasome in neuronal cells. Toxicology 2015;334:104-110.

180 Genovese T, Mazzon E, Paterniti I, Esposito E, Bramanti P, Cuzzocrea S: Modulation of NADPH oxidase activation in cerebral ischemia/reperfusion injury in rats. Brain Res 2011;1372:92-102.

181 Wedgwood S, Lakshminrusimha S, Farrow KN, Czech L, Gugino SF, Soares F, Russell JA, Steinhorn RH: Apocynin improves oxygenation and increases eNOS in persistent pulmonary hypertension of the newborn. Am J Physiol Lung Cell Mol Physiol 2012;302:L616-L626.

182 Paterniti I, Galuppo M, Mazzon E, Impellizzeri D, Esposito E, Bramanti P, Cuzzocrea S: Protective effects of apocynin, an inhibitor of NADPH oxidase activity, in splanchnic artery occlusion and reperfusion. J Leukoc Biol 2010;88:993-1003.

183 Impellizzeri D, Mazzon E, Esposito E, Paterniti I, Bramanti P, Cuzzocrea S: Effect of apocynin, an inhibitor of NADPH oxidase, in the inflammatory process induced by an experimental model of spinal cord injury. Free Radic Res 2011;45:221-236.

184 Impellizzeri D, Esposito E, Mazzon E, Paterniti I, Di Paola R, Bramanti P, Cuzzocrea S: Effect of apocynin, a NADPH oxidase inhibitor, on acute lung inflammation. Biochem Pharmacol 2011;81:636-648.

185 Roe ND, Thomas DP, Ren J: Inhibition of NADPH oxidase alleviates experimental diabetes-induced myocardial contractile dysfunction. Diabetes Obes Metab 2011;13:465-473.

186 Ahmad A, Mondello S, Di Paola R, Mazzon E, Esposito E, Catania MA, Italiano D, Mondello P, Aloisi C, Cuzzocrea S: Protective effect of apocynin, a NADPH-oxidase inhibitor, against contrast-induced nephropathy in the diabetic rats: a comparison with n-acetylcysteine. Eur J Pharmacol 2012;674:397-406.

187 Jackman KA, Miller AA, De Silva TM, Crack PJ, Drummond GR, Sobey CG: Reduction of cerebral infarct volume by apocynin requires pretreatment and is absent in Nox2-deficient mice. Br J Pharmacol 2009;156:680-688.

188 Kelly KA, Li X, Tan Z, VanGilder RL, Rosen CL, Huber JD: NOX2 inhibition with apocynin worsens stroke outcome in aged rats. Brain Res 2009;1292:165-172.

189 Tang XN, Cairns B, Cairns N, Yenari MA: Apocynin improves outcome in experimental stroke with a narrow dose range. Neuroscience 2008;154:556-562.

190 Xing PP, Wu WH, Du P, Han FM, Chen Y: Effects of brucine combined with glycyrrhetinic acid or liquiritin on rat hepatic cytochrome P450 activities in vivo. Yao Xue Xue Bao 2011;46:573-580.

191 Okuma Y, Liu K, Wake H, Liu R, Nishimura Y, Hui Z, Teshigawara K, Haruma J, Yamamoto Y, Yamamoto H, Date I, Takahashi HK, Mori S, Nishibori M: Glycyrrhizin inhibits traumatic brain injury by reducing HMGB1-RAGE interaction. Neuropharmacology 2014;85:18-26.

192 Kim SW, Jin Y, Shin JH, Kim ID, Lee HK, Park S, Han PL, Lee JK: Glycyrrhizic acid affords robust neuroprotection in the postischemic brain via anti-inflammatory effect by inhibiting HMGB1 phosphorylation and secretion. Neurobiol Dis 2012;46:147-156.

193 Huang J, Liu B, Yang C, Chen H, Eunice D, Yuan Z: Acute hyperglycemia worsens ischemic stroke-induced brain damage via high mobility group box-1 in rats. Brain Res 2013;1535:148-155.

194 Zhang J, Wu Y, Weng Z, Zhou T, Feng T, Lin Y: Glycyrrhizin protects brain against ischemia-reperfusion injury in mice through HMGB1-TLR4-IL-17A signaling pathway. Brain Res 2014;1582:176-186.

195 Barakat W, Safwet N, El-Maraghy NN, Zakaria MN: Candesartan and glycyrrhizin ameliorate ischemic brain damage through downregulation of the TLR signaling cascade. Eur J Pharmacol 2014;724:43-50.

196 Di Paola R, Menegazzi M, Mazzon E, Genovese T, Crisafulli C, Dal Bosco M, Zou Z, Suzuki H, Cuzzocrea S: Protective effects of glycyrrhizin in a gut hypoxia (ischemia)-reoxygenation (reperfusion) model. Intensive Care Med 2009;35:687-697.

197 Menegazzi M, Di Paola R, Mazzon E, Genovese T, Crisafulli C, Dal Bosco M, Zou Z, Suzuki H, Cuzzocrea S: Glycyrrhizin attenuates the development of carrageenan-induced lung injury in mice. Pharmacol Res 2008;58: $22-31$. 
198 Genovese T, Menegazzi M, Mazzon E, Crisafulli C, Di Paola R, Dal Bosco M, Zou Z, Suzuki H, Cuzzocrea S: Glycyrrhizin reduces secondary inflammatory process after spinal cord compression injury in mice. Shock 2009; 31:367-375.

199 Liang B, Guo XL, Jin J, Ma YC, Feng ZQ: Glycyrrhizic acid inhibits apoptosis and fibrosis in carbon-tetrachlorideinduced rat liver injury. World J Gastroenterol 2015;21:5271-5280.

200 Abe K, Ikeda T, Wake K, Sato T, Sato T, Inoue H: Glycyrrhizin prevents of lipopolysaccharide/D-galactosamineinduced liver injury through down-regulation of matrix metalloproteinase- 9 in mice. J Pharm Pharmacol 2008;60:91-97.

201 Jiang RW, Lau KM, Hon PM, Mak TC, Woo KS, Fung KP: Chemistry and biological activities of caffeic acid derivatives from Salvia miltiorrhiza. Curr Med Chem 2005;12:237-246.

202 Liang G, Shi B, Luo W, Yang J: The protective effect of caffeic acid on global cerebral ischemia-reperfusion injury in rats. Behav Brain Funct 2015;11:18.

203 Pinheiro Fernandes FD, Fontenele Menezes AP, de Sousa Neves JC, Fonteles AA, da Silva AT, de Araujo Rodrigues P, Santos do Carmo MR, de Souza CM, de Andrade GM: Caffeic acid protects mice from memory deficits induced by focal cerebral ischemia. Behav Pharmacol 2014;25:637-647.

204 Zhou Y, Fang SH, Ye YL, Chu LS, Zhang WP, Wang ML, Wei EQ: Caffeic acid ameliorates early and delayed brain injuries after focal cerebral ischemia in rats. Acta Pharmacol Sin 2006;27:1103-1110.

205 Ketsawatsakul U, Whiteman M, Halliwell B: A reevaluation of the peroxynitrite scavenging activity of some dietary phenolics. Biochem Biophys Res Commun 2000;279:692-699.

206 Park WH, Kim SH, Kim CH: A new matrix metalloproteinase-9 inhibitor 3,4-dihydroxycinnamic acid (caffeic acid) from methanol extract of Euonymus alatus: isolation and structure determination. Toxicology 2005;207: 383-390.

207 Chen Y, Wu X, Yu S, Fauzee NJ, Wu J, Li L, Zhao J, Zhao Y: Neuroprotective capabilities of tanshinone IIA against cerebral ischemia/reperfusion injury via anti-apoptotic pathway in rats. Biol Pharm Bull 2012;35:164-170.

208 Liu L, Zhang X, Wang L, Yang R, Cui L, Li M, Du W, Wang S: The neuroprotective effects of Tanshinone IIA are associated with induced nuclear translocation of TORC1 and upregulated expression of TORC1, pCREB and BDNF in the acute stage of ischemic stroke. Brain Res Bull 2010;82:228-233.

209 Dong K, Xu W, Yang J, Qiao H, Wu L: Neuroprotective effects of tanshinone IIA on permanent focal cerebral ischemia in mice. Phytother Res 2009;23:608-613.

210 Chen Y, Wu X, Yu S, Lin X, Wu J, Li L, Zhao J, Zhao Y: Neuroprotection of tanshinone IIA against cerebral ischemia/reperfusion injury through inhibition of macrophage migration inhibitory factor in rats. PLoS One 2012; 7:e40165.

211 Tang C, Xue H, Bai C, Fu R, Wu A: The effects of tanshinone IIA on blood-brain barrier and brain edema after transient middle cerebral artery occlusion in rats. Phytomedicine 2010;17:1145-1149.

212 Wang L, Zhang X, Liu L, Cui L, Yang R, Li M, Du W: Tanshinone II A down-regulates HMGB1, RAGE, TLR4, NF- $\mathrm{kB}$ expression, ameliorates BBB permeability and endothelial cell function, and protects rat brains against focal ischemia. Brain Res 2010;1321:143-151.

213 Wang JG, Bondy SC, Zhou L, Yang FZ, Ding ZG, Hu Y, Tian Y, Wen PY, Luo H, Wang F, Li WW, Zhou J: Protective effect of tanshinone IIA against infarct size and increased HMGB1, NFkappaB, GFAP and apoptosis consequent to transient middle cerebral artery occlusion. Neurochem Res 2014;39:295-304.

214 Hu H, Zhai C, Qian G, Gu A, Liu J, Ying F, Xu W, Jin D, Wang H, Hu H, Zhang Y, Tang G: Protective effects of tanshinone IIA on myocardial ischemia reperfusion injury by reducing oxidative stress, HMGB1 expression, and inflammatory reaction. Pharm Biol 2015;53:1752-1758.

215 Turner RS, Thomas RG, Craft S, van Dyck CH, Mintzer J, Reynolds BA, Brewer JB, Rissman RA, Raman R, Aisen PS: Alzheimer's Disease Cooperative Study; A randomized, double-blind, placebo-controlled trial of resveratrol for Alzheimer disease. Neurology 2015;85:1383-1391.

216 Sanmukhani J, Satodia V, Trivedi J, Patel T, Tiwari D, Panchal B, Goel A, Tripathi CB: Efficacy and safety of curcumin in major depressive disorder: a randomized controlled trial. Phytother Res 2014;28:579-585.

217 Fagan SC, Lapchak PA, Liebeskind DS, Ishrat T, Ergul A: Recommendations for preclinical research in hemorrhagic transformation. Transl Stroke Res 2013;4:322-327.

218 Henning EC, Latour LL, Hallenbeck JM, Warach S: Reperfusion-associated hemorrhagic transformation in SHR rats: evidence of symptomatic parenchymal hematoma. Stroke 2008;39:3405-3410.

219 Zhao BQ, Wang S, Kim HY, Storrie H, Rosen BR, Mooney DJ, Wang X, Lo EH: Role of matrix metalloproteinases in delayed cortical responses after stroke. Nat Med 2006;12:441-445.

220 Hayakawa K, Pham LD, Katusic ZS, Arai K, Lo EH: Astrocytic high-mobility group box 1 promotes endothelial progenitor cell-mediated neurovascular remodeling during stroke recovery. Proc Natl Acad Sci USA 2012; 109:7505-7510. 